مجلة اتحاد الجامعات العربية للعلوم الزراعية، جامعة عين شمس، القاهرة، مصر مجلد(28)، عدد(3)، 714-695، 2020

أحمد محمد فراج قاسم1 - - نور ممدوح عيسى طنطاوي1 1 - تامر محمد عبد الصادق السنتريسي2*

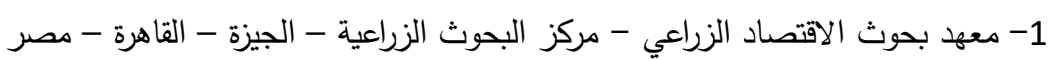

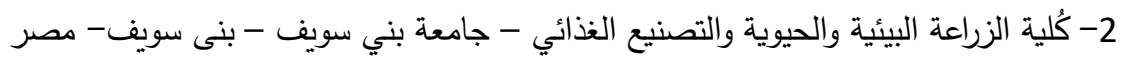

*Corresponding author: Dr Tamer@agr.bsu.edu.eg

Received 5 September, 2020 Accepted 26 September, 2020

المُترتبة على تحقيق الكفاءة التقنية في إنتاج الطماطم الصيفي على مُستوى العينة البحثية ومنطقة البحث

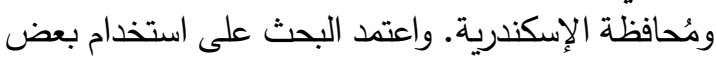
أساليب التحليل الاقتصادي الوصفي والكمي في تحليل

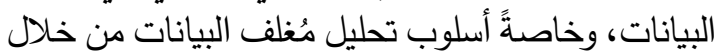
تطبيق نمُوذجيه: (CCR) الذي يستند إلى فرضية ثبات

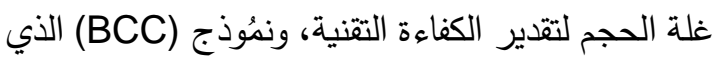
يستند إلى فرضية تغير غلة الحجم لتقدير كُل من الكفاءة

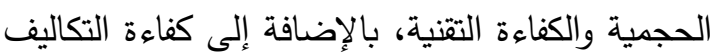

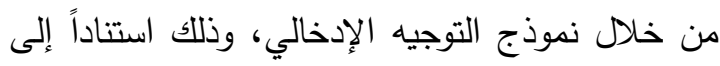
البيانات الميدانية لعينة عشوائية تم تجميعها خلادل موسم

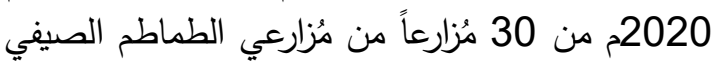
بإدارة العامرية الزراعية في مُحافظة الإسكندرية. منرائ.

الكلمات المفتاحية: تحليل مُغلف البيانات، الكفاءة

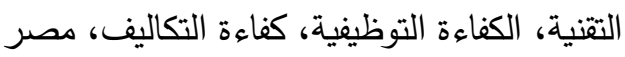

\section{المُقدمةة}

تُشكل محاصيل الخُضر جزءاً هاماً في غذاء الإنسان لإحتوائها على نسبة كبيرة من الكربوهيدرات، الفيتامينات والأملاح المعدنية التي يحتاجها الإنسان في غذائهائه، وتتميز الخُضر بأنها سريعة النمُو لذلك يهتم المُزارعُون

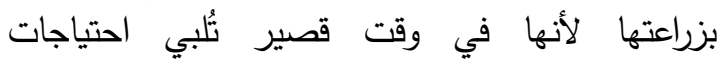
المُستهلكين وتُحقق عائد يفُوق كثيراً المحاصيل الأخرى، وقد بلغت المساحة المزرُوعة من الخضر في فئ مصر حوالي 1,84 مليُون فدان بنسبة تُمثل نحو 11,5\% من

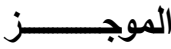

بالرغم من أن المساحة المزرُوعة بالطماطم الصيفي في مُحافظة الإسكندرية تُمثل نحو 18,5\% من إجمالي

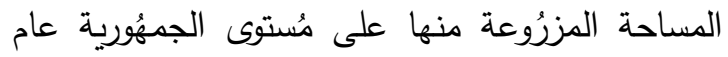

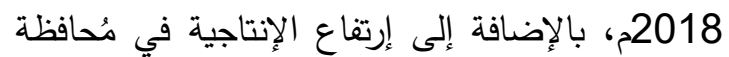

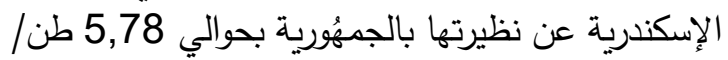
فدان خلال نفس العام، إلا أن دُخول المُزارعين من إنتاج

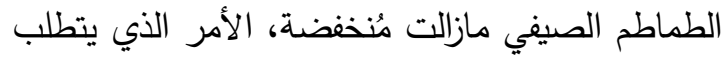

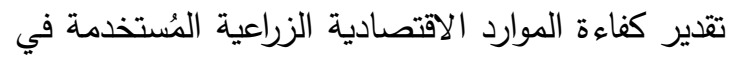

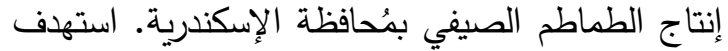

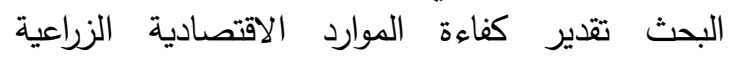
المُستخدمة في إنتاج الطماطم الصيفي بمُحافظة الإسكندرية، وذلك من خلال: (1) دراسة الطاقة الإنتاجية للطماطم الصيفي في الجمهُورية ومُحافظة الإسكندرية

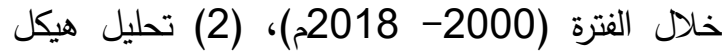

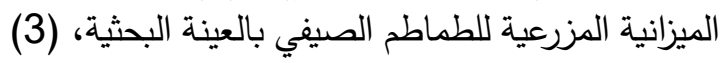

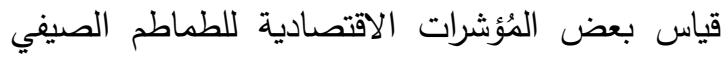

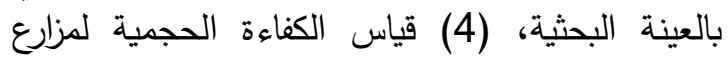

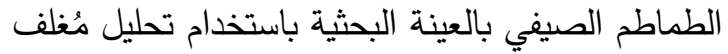

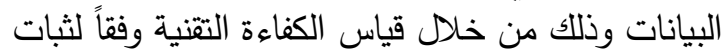

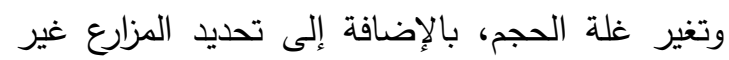

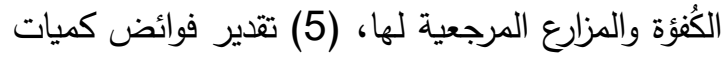

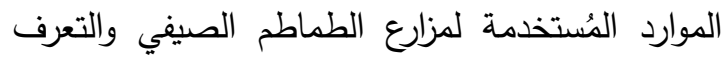

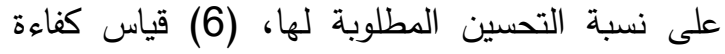

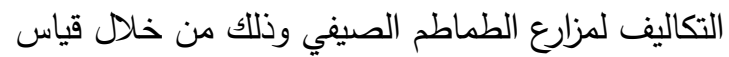
الكفاءة التقنية والتوظيفية، (7) قياس الآثار الاقتصادية 
البحثية، (4) قياس الكفاءة الحجمية لمزارع الطماطم

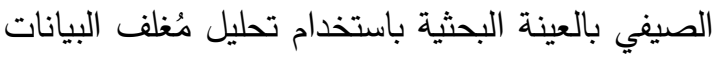

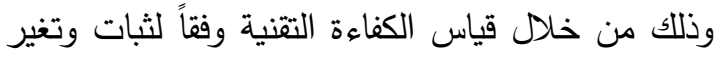
غلة الحجم، بالإضافة إلى تحديد المزارع غير الكياءة الكُؤئة والمزارع المرجعية لها، (5) تقدير فوائض كميات الموالئ الموارد

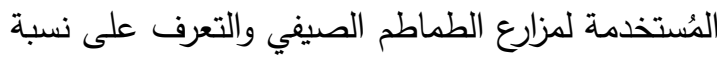

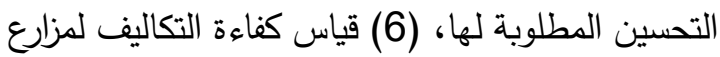

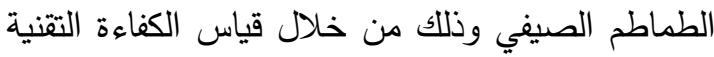

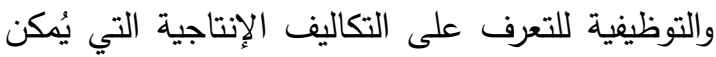

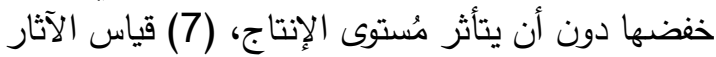

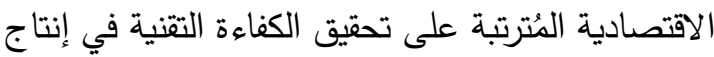

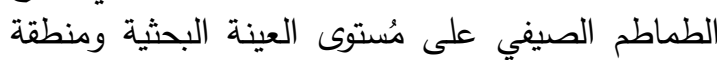
البحث ومُحافظة الإسكندرية.

الأسلوب البحثي الاقتصادي الوصفي والكمي في تحليل البيانات، والتي لتئي

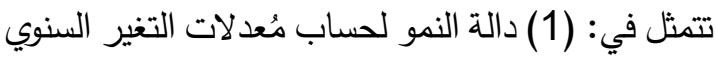

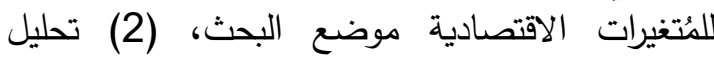

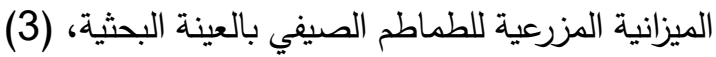

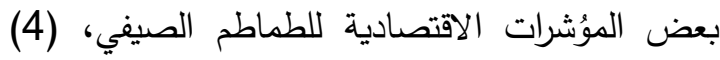

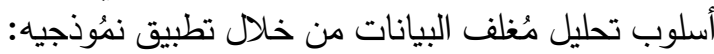

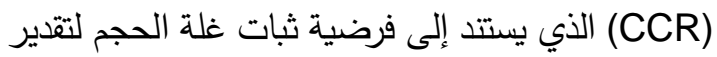

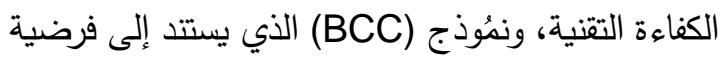
تغير غلة الحجم لتقدير كُل من الكفاءة الحجمية والكفاءئل الكفاءة

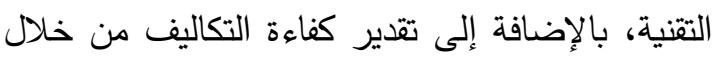

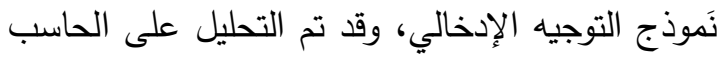
الآلي باستخدام برنامج تحليل مُغلف الإنف تلبيانات الإصدار

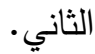

الإطار النظري للبحث

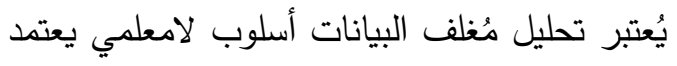

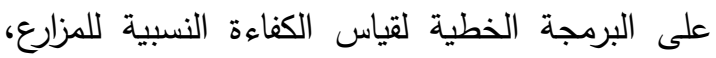
والذي أشارت إليه دراسة (Farrell, 1957) لقياس لفزاءعة

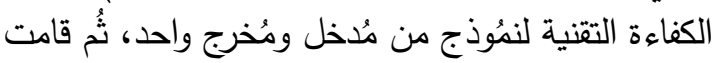
(Charnes, Cooper and Rhodes, دراسة (1978 بتطوير النمُوذج إلى نمُوذج مُتعدد المُدخلات

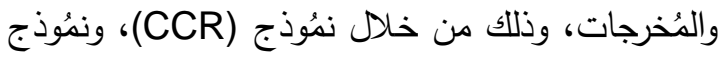

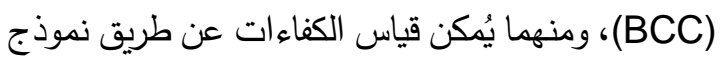

إجمالي المساحة المحصُولية والبالغة قرابة 16 مليُون فدان خلال مُتوسط الفترة (2016- 2018م) . وتُعتبر الطماطم من المحاصيل الخُضرية الهامة في لئري التركيب المحصولي المصري، حيث المئ بلغت المساحة

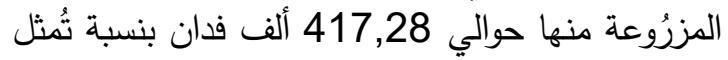
نحو 22,68 من إجمالي مساحة الخُضر بالجمهُورية

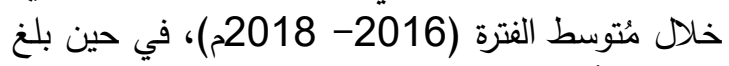

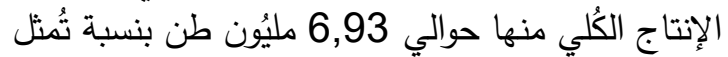

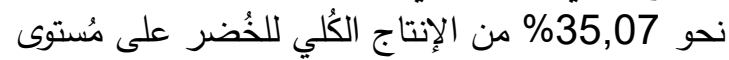

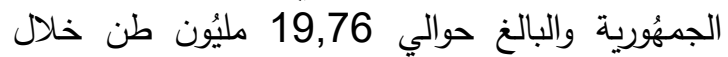
مُتوسط نفس الفترة، وتُستهلَك الطماطم محلياً بكميات كبيرة باعتبارها جانب رئيسي من مُكونات الغذاء اليومي فئي

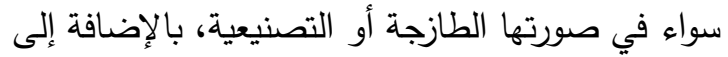

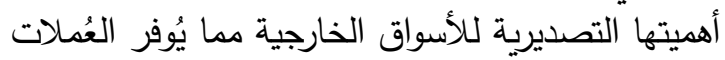

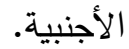

\section{المُشكلة البحثية}

بالرغم من أن المساحة المزرُوعة بالطماطم الصيفي

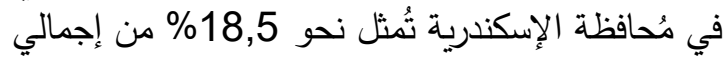

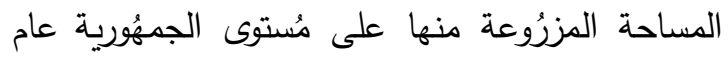

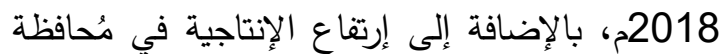

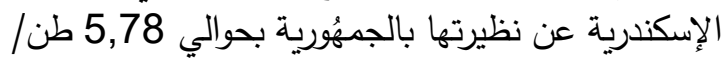

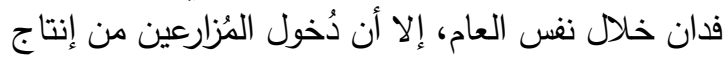

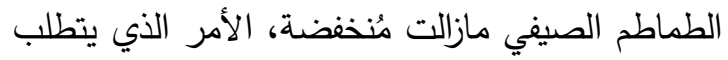

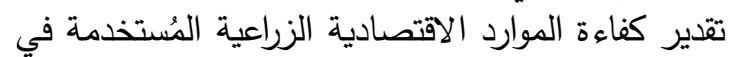

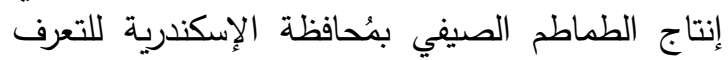
على مدى انحراف تلك الموارد عن الاستخدام الأمثل.

\section{الأهداف البحثية}

يستهدف البحث بصفة رئيسية تقدير كفاءة الموارد

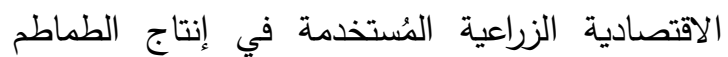

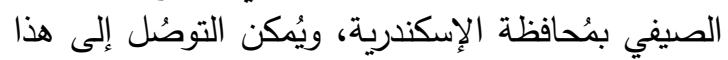

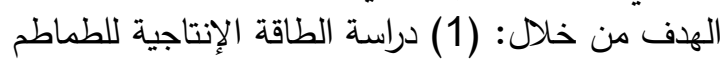
الصيفي في الجمهُورية ومُحافظة الإسكندرية خلال الفترة

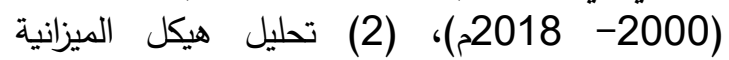
المزرعية للطماطم الصيفي بالعينة البحثية، (3) قياس بعض المُؤشرات الاقتصادية للطماطم الصيفي بالعينة 
ويُوضــــ شـكل (1) الكفاءة التقتية والتوظيفية وكفاءة التكاليف وفقاً لنموذج التوجية الإدخالي، وذللك كما يلي:

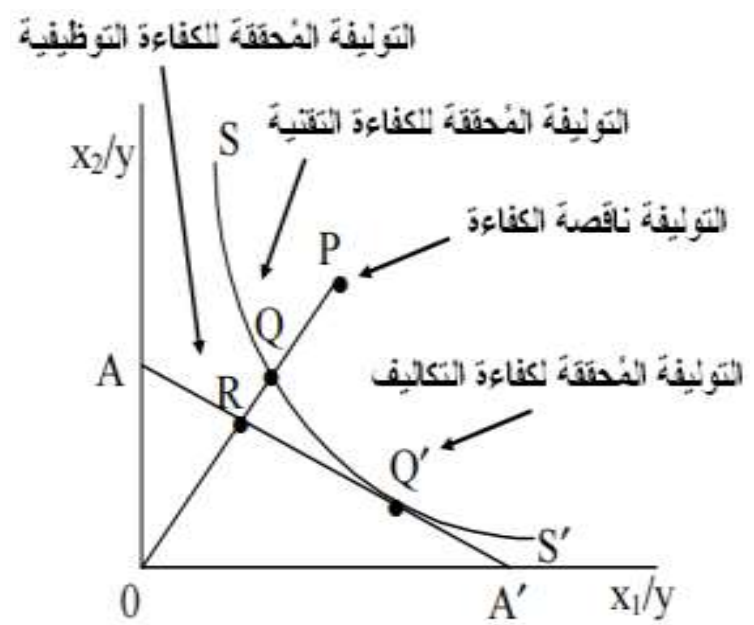

شكل 1. الكفاءة التقنية والتوظيفية وكفاءة التكاليف وفقاً

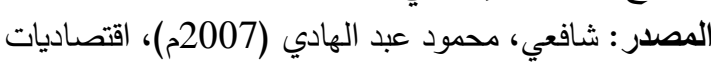

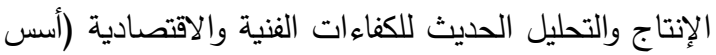

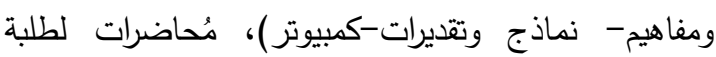

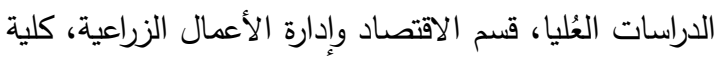

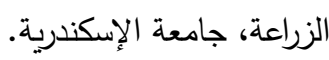

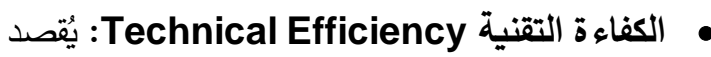
بإها قُرة المزرعة على تحقيق أقصى إنتاج مُمكن

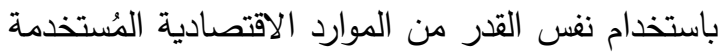

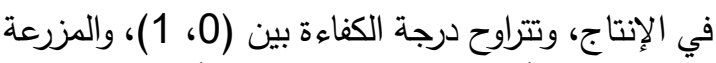

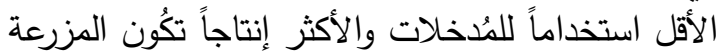

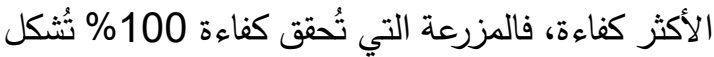

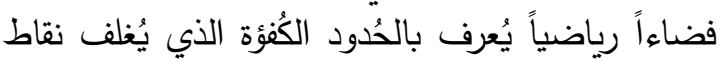

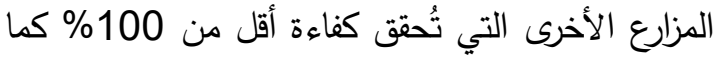
تُوُضِحِح التوليفة (Q) على منحنى الناتج المُتساوي، ولذلك سُمِيَ بتحليل مُنفلف البيانات.

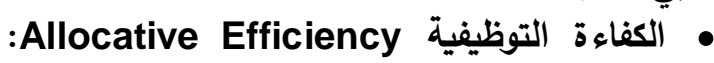

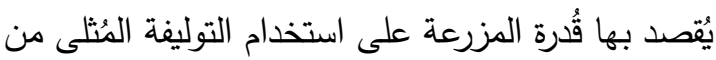

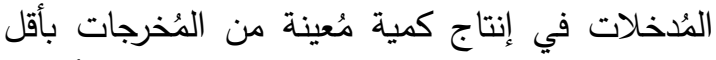
تكلفة مُكنة وذلك مع الأخذ في الإعتبار أسعار

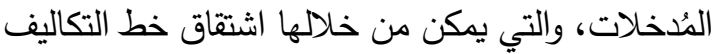

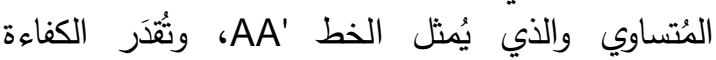

التوجيه الإدخالي والذي تعود مرجعيته إلى مُنحنى الناتج

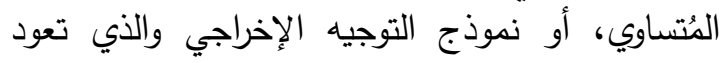

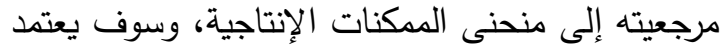

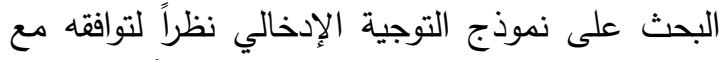

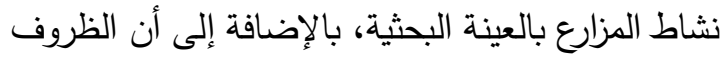

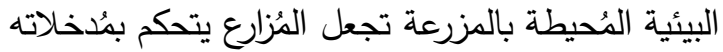
أكثر من سيطرته على زيادة الإنتاج.

$$
\text { (أ) نمُوذج (CCR) }
$$

(Charnes, Cooper \& يُعرف نموذج (C) Constant بعوائد الحجم الثابتة Rhodes,1978) Returns to Scale (CRS)

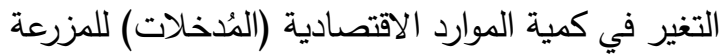

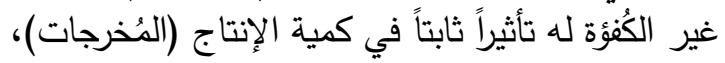

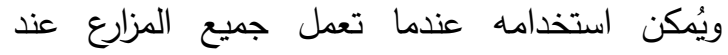

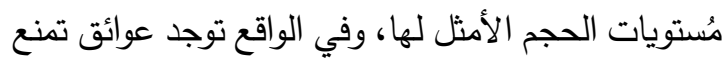
المزارع من تحقيق الأحجام اليُّلى لها.

$$
\text { (ب) نمُوذج (BCC) }
$$

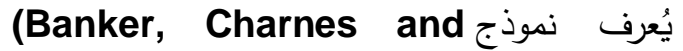
(VRS) بعوائد الحجم اليُتغيرة Cooper, 1984) Variable Returns to Scale لنمُوذج (CCR)، ويتميز عليه بأنه يتطرق إلى نئى اقتصاديات الحجم.

• الكفاءة الحجمية Scale Efficiency: يُّصد بها

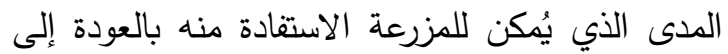
الحجم الأمثل الذي تتساوى عنده الكفاءة الحجمية بالواحد

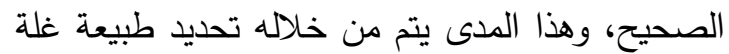

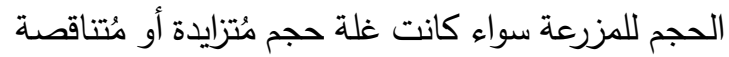

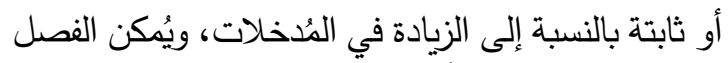
بين الكفاءة التقنية وفقاً لثبات وتغير غلة الثلة الحجم من خلال

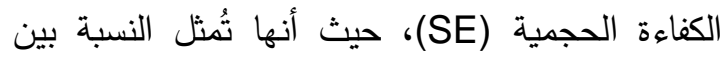

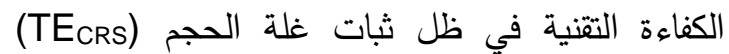

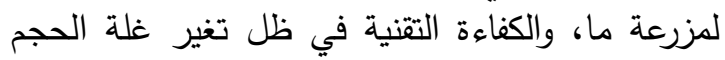

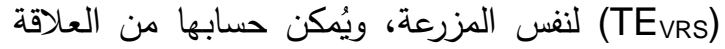

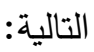
$\mathrm{SE}=\mathrm{TE}_{\mathrm{CRS}} / \mathrm{TE}_{\mathrm{VRS}}$ 


$$
\text { قاسم - نورا طنطاوي - السنتريسي }
$$

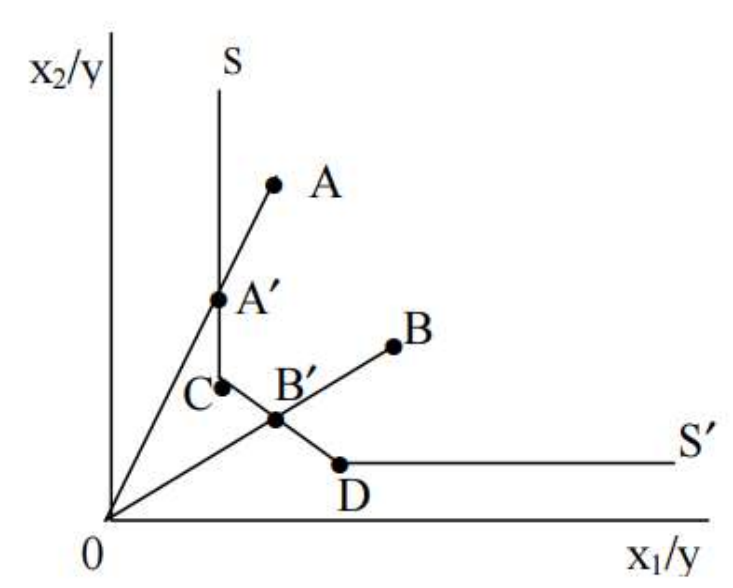

شكل 2. تقدير فوائض المُحخلات والوحدات المرجعية اللمزارع غير الكؤوة

المصدر: شافعي، محمود عبد الهادي (2007م)، اقتصاديات الإنتاج والتحليل الحديث للكفاء ات الفنية والاقتصادية (أسسادي

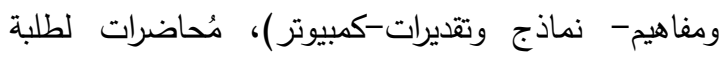

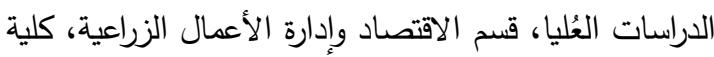

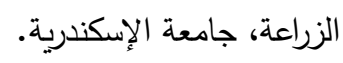

• • المزارع المرجعية Peers: يُّْد بها المزارع الكُؤَة

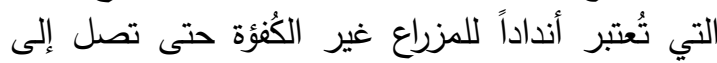

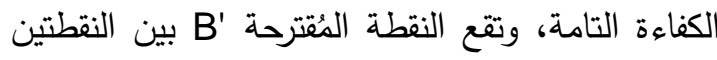

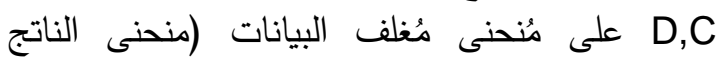
الأُستاوي)، ويُطلق على هاتين النقطتين( المزرعتين) وحدات مرجعية للنقطة (للمزرعة) النطين

مصادر البيانات واختيار العينة البحثية اعتد البحث على مصدرين للبيانات، أولهمها:

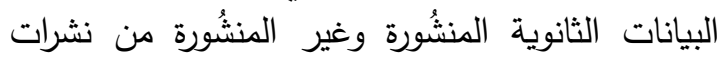

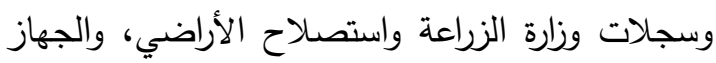

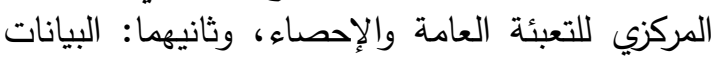

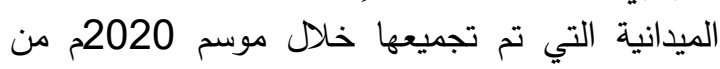
بعض مُزارعي الطماطم الصيفي بإدارة العامرية الزراعية

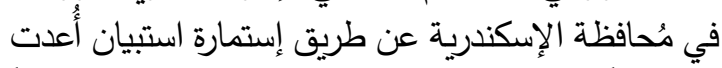
خصيصاً لهذا الغرض، حيث تم إختيار 30 مُزارعاً

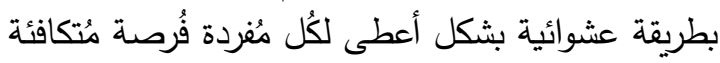
للظهور في العينة، وقد تم اختيار الطماطم الصيفي لُعني لأنها أكبر مسأحة مزروعة بمُحافظة الإسكندرية مُقُارنةً
التوظيفية عند النقطة R، ويُكن حسابها من العلاقة

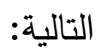
$A E=O R / O Q$

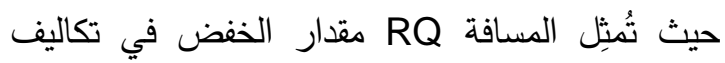
الإنتاج المُُكن تحقيقه، أي أن التوليفة Q تُحقق الكفاءة

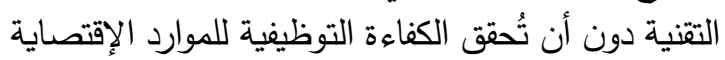
المُستخدمة في الإنتاج. • كفاءة التكاليف Cost Efficiency: يُقَد بهاج قُُرة المزرعة في الحضُول على قدر معين من الإنتاج

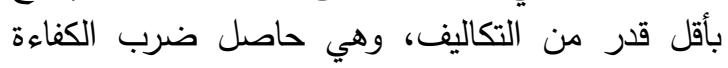
التتنية (TE) والكفاءة التوظيفية (AE)، وتُشثل النقطة النقطة المُحققة للكفاءة التوظيفية والتقنية معاً من التعنية خلال تقاطع ميل خط التكاليف الئتساوي (النسبة السعرية

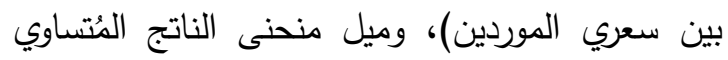

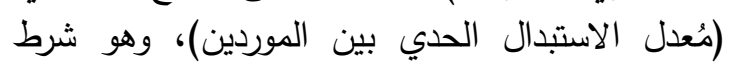
تحقيق كفاءة التكاليف، ويُمكن حسابها من العلاقة الإنة

$$
C E=(T E) \times(A E)
$$

وتتمثل شروط استخدام تحليل مغلف البيانات فيما يلي: (1) أن تكون المزارع من نفس نول نوع النشاط الاقتصادي،

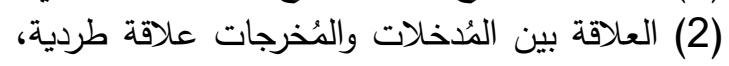

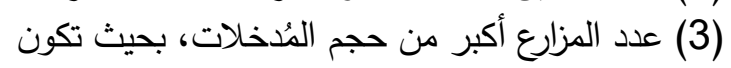

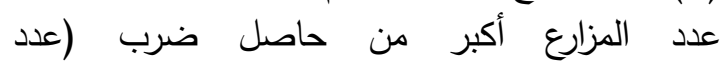
المدخلات×عدد المخرجات) أو عدد المزات المزارع أكبر من (عند حاصل 3× (عدد الدخخلات+عدد المخرجات).

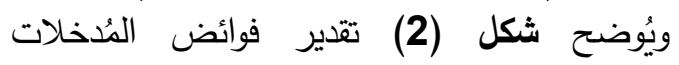
والوحدات المرجعية للمزارع غير الكفؤة، وذللك كما يلي: • الفوائض Slacks والتحسين المُطلوب للمُّخلات:

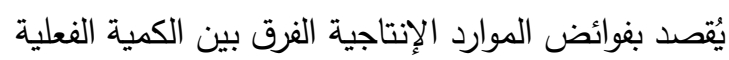

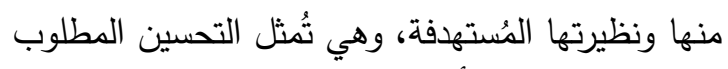

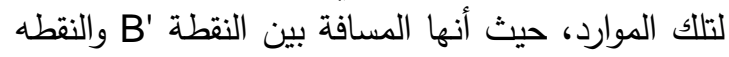

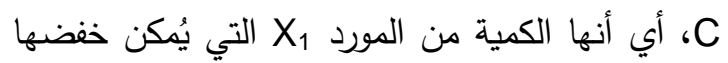

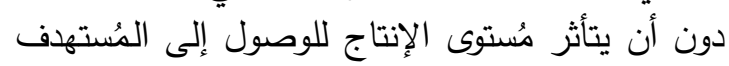

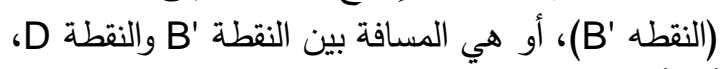

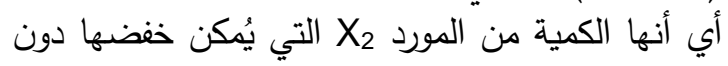

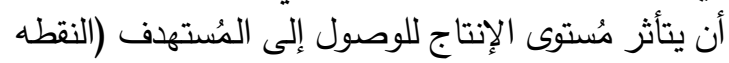


وحد أقصى بلغ حوالي 49,17 ألف فدان عام 2008م، وقد ثبتت عدم معنوية المساحة المزرُوعة بمُحافظة

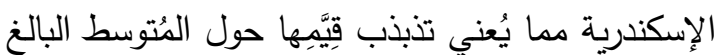

حوالي 37,23 ألف فدان - معادلة (1). وتراوحت المساحة المزرُوعة بالجمهُورية بين حدان حدان

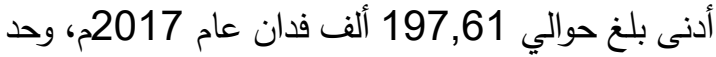

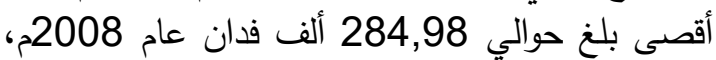
وقد ثبتت عدم المعنوية الإحصائية للمساحة المزرُوعة بالجمهُورية مما يُعني تذبذب قِيَّمها حول المُتوسط البالغ حوالي 234,29 ألف فدان - معادلة (4).

(2) (الإنتاجية الفدانية تراوحت الإنتاجية الفدانية بمُحافظة الإسكندرية بين

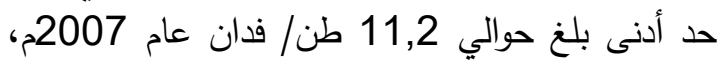

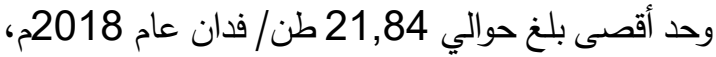
وقد ازدادت الإنتاجية الفدانية خلال فترة البحث بمُعدل نمو سنوي معنوي إحصائياً قُدر بنحو الفترة والبالغ حوالي 16,68 طن/ فدان - معادلة (2).

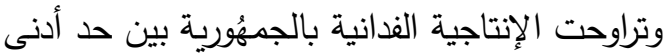

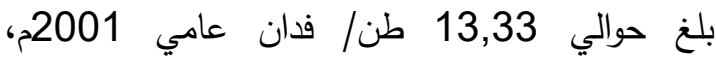
2002م، وحد أقصى بلغ حوالي 16,29 طن/ فن فان

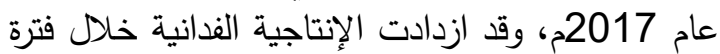
البحث بمُعدل نمو سنوي معنوي إحصائياً قُدِر بنحو

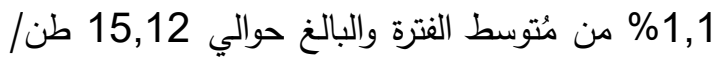

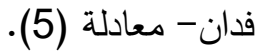

$$
\text { (3) (الإنتاج الكُلي }
$$

تراوح الإنتاج الكلي بمُحافظة الإسكندرية بين حد الإنياج

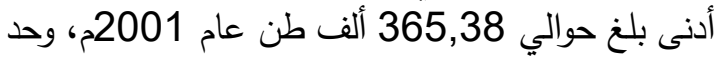

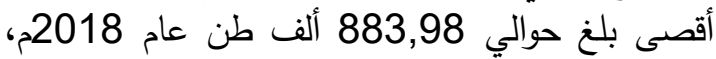
وقد ازداد الإنتاج الكلي خلال فترة البحث بمُعدل نمو لمون

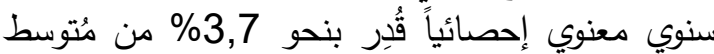

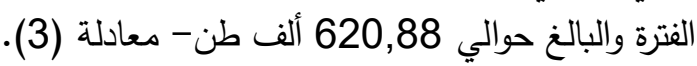
تراوح الإنتاج الكلي بالجمهُورية بين حد أدنى بلغ الغن

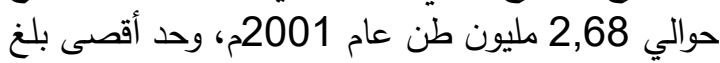
حوالي 4,23 مليون طن عام 2009م، وقد ازداد الإنتاج

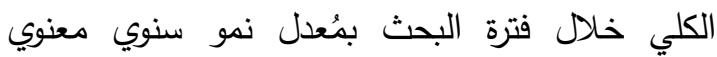

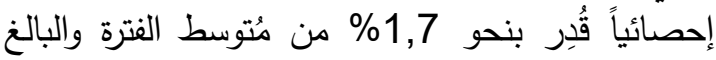

حوالي 3,54 مليون طن - معادلة (6) بهن مثنائ
بمحاصيل الخضر الأخرى حيث بلغت المساحة المرزوعة بها حوالي 35,14 ألف فدان بنسبة تُمثل نحو الخد

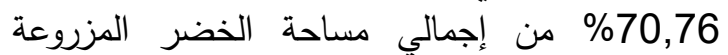
بمُحافظة الإسكندرية والبالغة حوالي 49,66 ألف فدان خلال موسم 2020م، وقد تم اختيار إدارة العامرية

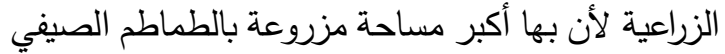

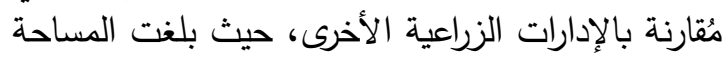

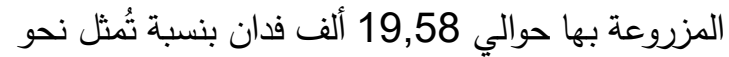

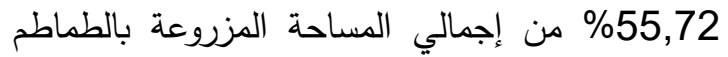

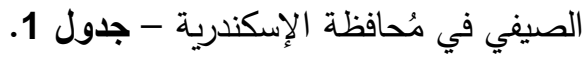
جدول 1. المساحة المزروعة بالطماطم الصيفي وأهميتها النسبية في الإدارات الزراعية بُحافظة الإسكندرية خلال

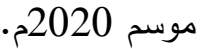

\begin{tabular}{|c|c|c|}
\hline \multicolumn{2}{|c|}{ المساحة } & البيان \\
\hline (الإجمالي & (فدان) & الإدارة \\
\hline 55.72 & 19575 & العامريـة \\
\hline 39.31 & 13812 & بُرج العرب \\
\hline 4.80 & 1688 & خُورشيد \\
\hline 0.17 & 61 & المعمُورة \\
\hline 100 & 35136 & الإجمالى \\
\hline
\end{tabular}

المصدر: جُمِعتٌ وحُسِبتٌ من: وزارة الزراعة واستصلاح

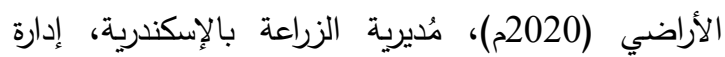

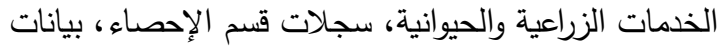

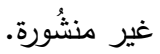

\section{نتائج البحث ومُناقشتها}

أولاً: الطاقة الإنتاجية للطماطم الصيفي في مُحافظة

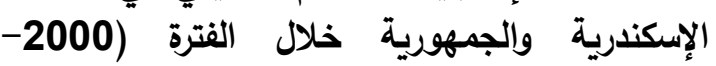
2018 يُيين جدولي 2018، 3 البيانات المُتعلقة بتطور مساحة وإنتاجية وإنتاج الطماطم الصيفي في مُحافظة الإسكندرية والجمهُورية ما يلي: وانتئية

(1) - (1) المساحة المزروعة تراوحت المساحة المزروعة بمُحافظة الإسكندرية بين

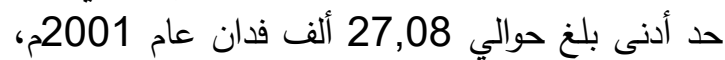


جدول 2. تطور مساحة وإنتاجية وإنتاج الطماطم الصيفي في مُحافظة الإسكندرية والجمهُورية خلال الفترة (2000.) 2018

\begin{tabular}{|c|c|c|c|c|c|c|c|c|c|}
\hline \multicolumn{3}{|c|}{ الإنتاج الكلي (ألف طن) } & \multicolumn{3}{|c|}{ الإنتاجية (طن/ فدان) } & \multicolumn{3}{|c|}{ المساحة المزروعة (ألف فدان) } & \multirow{2}{*}{ السنوات } \\
\hline$\%$ & الجمهُورية & الإسكندرية & $\%$ & الجمهُورية & الإسكندرية & $\%$ & الجمهُورية & الإسكندرية | & \\
\hline 18.46 & 2831.02 & 522.55 & 108.29 & 13.39 & 14.50 & 17.05 & 211.37 & 36.04 & 2000 \\
\hline 13.64 & 2677.84 & 365.38 & 101.20 & 13.33 & 13.49 & 13.48 & 200.86 & 27.08 & 2001 \\
\hline 15.84 & 2707.55 & 428.91 & 104.65 & 13.33 & 13.95 & 15.14 & 203.08 & 30.75 & 2002 \\
\hline 18.22 & 2804.46 & 510.96 & 100.00 & 13.77 & 13.77 & 18.23 & 203.61 & 37.11 & 2003 \\
\hline 13.97 & 2931.96 & 409.46 & 94.78 & 14.76 & 13.99 & 14.73 & 198.70 & 29.27 & 2004 \\
\hline 17.32 & 3288.92 & 569.72 & 94.23 & 15.26 & 14.38 & 18.39 & 215.46 & 39.63 & 2005 \\
\hline 13.15 & 3586.79 & 471.54 & 89.03 & 14.86 & 13.23 & 14.78 & 241.31 & 35.66 & 2006 \\
\hline 10.33 & 3865.06 & 399.28 & 77.35 & 14.48 & 11.20 & 13.36 & 266.96 & 35.66 & 2007 \\
\hline 18.04 & 4233.95 & 763.84 & 104.51 & 14.86 & 15.53 & 17.25 & 284.98 & 49.17 & 2008 \\
\hline 19.29 & 4233.98 & 816.63 & 113.35 & 15.66 & 17.75 & 17.02 & 270.32 & 46.02 & 2009 \\
\hline 17.98 & 4121.07 & 740.86 & 108.65 & 15.73 & 17.09 & 16.54 & 262.05 & 43.34 & 2010 \\
\hline 18.32 & 3793.66 & 694.94 & 113.77 & 15.40 & 17.52 & 16.10 & 246.36 & 39.67 & 2011 \\
\hline 18.86 & 4111.75 & 775.38 & 122.15 & 15.89 & 19.41 & 15.44 & 258.74 & 39.96 & 2012 \\
\hline 15.61 & 3853.34 & 601.67 & 112.49 & 16.17 & 18.19 & 13.88 & 238.38 & 33.09 & 2013 \\
\hline 16.13 & 4161.07 & 671.07 & 115.97 & 15.65 & 18.15 & 13.90 & 265.98 & 36.97 & 2014 \\
\hline 21.36 & 3850.77 & 822.67 & 129.79 & 15.91 & 20.65 & 16.46 & 242.10 & 39.84 & 2015 \\
\hline 17.97 & 3547.18 & 637.47 & 129.34 & 15.78 & 20.41 & 13.89 & 224.84 & 31.23 & 2016 \\
\hline 22.07 & 3218.28 & 710.4 & 119.52 & 16.29 & 19.47 & 18.47 & 197.61 & 36.49 & 2017 \\
\hline 25.15 & 3514.85 & 883.98 & 135.99 & 16.06 & 21.84 & 18.50 & 218.85 & 40.48 & 2018 \\
\hline- & 3543.87 & 620.88 & - & 15.12 & 16.68 & - & 234.29 & 37.23 & المُتتوسط \\
\hline- & 2677.84 & 365.38 & - & 13.33 & 11.20 & - & 197.61 & 27.08 & الحد الأدنى \\
\hline- & 4233.98 & 883.98 & - & 16.29 & 21.84 & - & 284.98 & 49.17 & الحد الأقصى \\
\hline
\end{tabular}

المصدر : جُمِعتُ وحُبِبتُ من: وزارة الزراعة واستصلاح الأراضي، قطاع الثئون الاقتصادية، الإدارة المركزية للاقتصاد الزراعي، نشرة الإحصاءات الزراعية، أعداد مُتْفرقة. 
جدول 3. مُعادلات الاتجاه العام لمساحة وإنتاجية وإنتاج الطماطم الصيفي في مُحافظة الإنكندرية والجمهُورية خلال الفترة (2000-2018م)

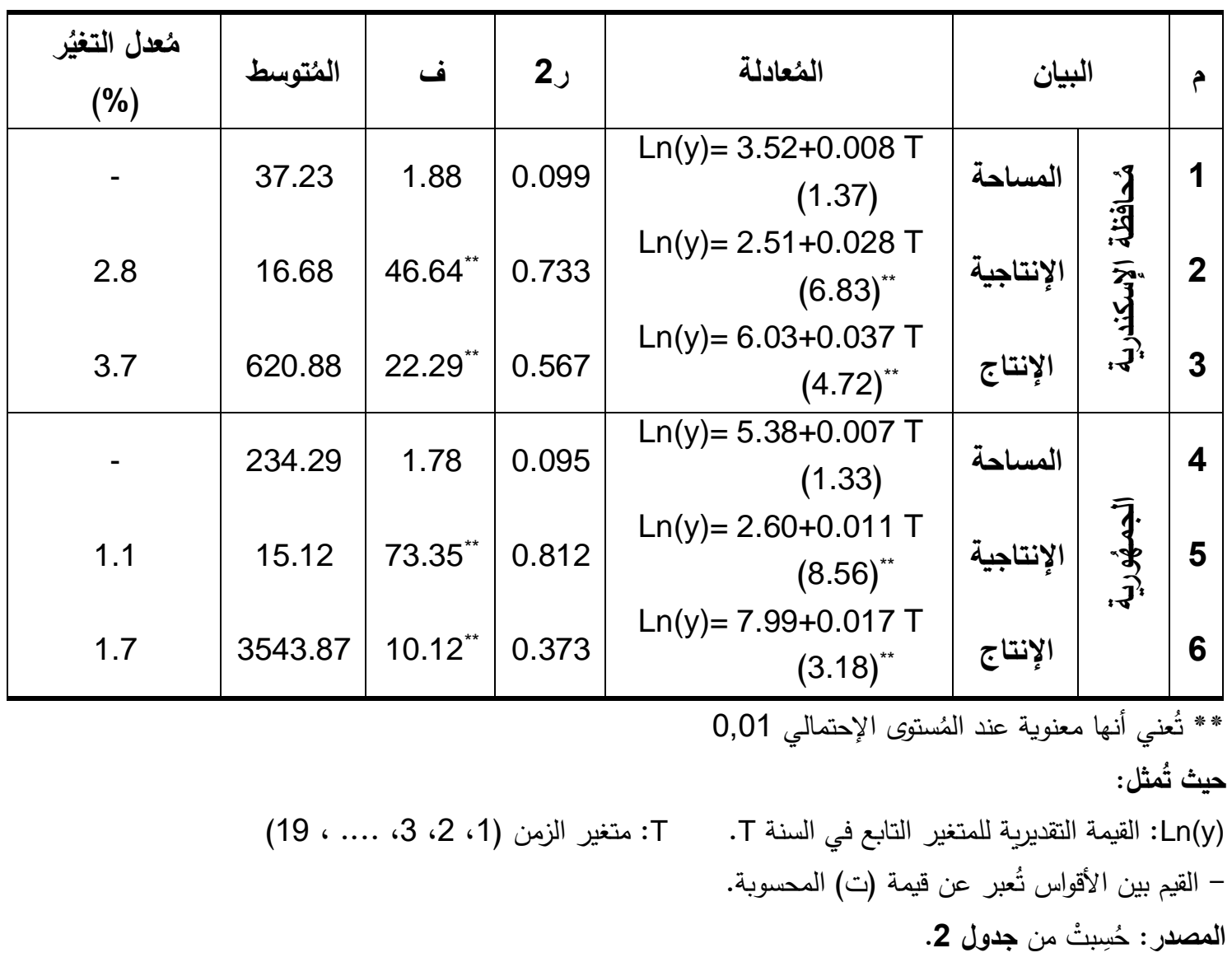

(أ) أُجور العمالة: بلغ مُتوسط الأُجور المُنفقة على إنتاج الطماطم الصيفي بالعينة البحثية حوالي الئل

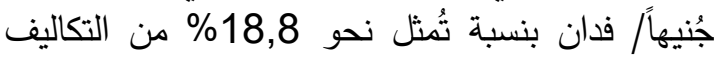

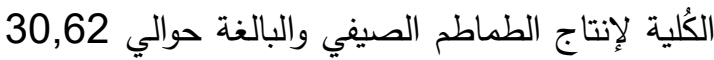

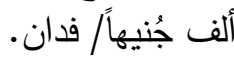

(ب) رأس المال المُستخدم: بلغ مُتوسط رأس المال

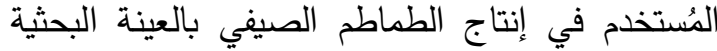

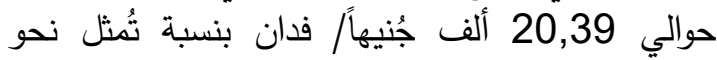
66,58 من التكاليف الكلية لإنتاج الطماطم الصيفي.

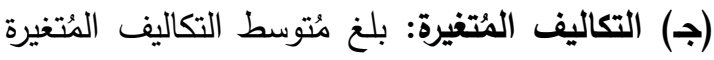

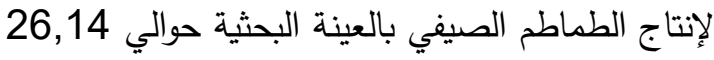

ثانياً: تحليل هيكل الميزانية المزرعية للطماطم الصيفي

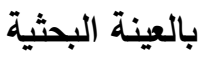
تتكون تكاليف الطماطم الصيفي بالعينة البحثية

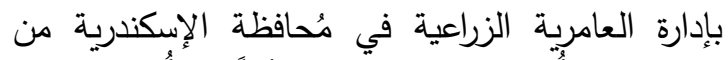

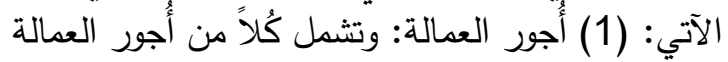

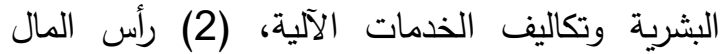

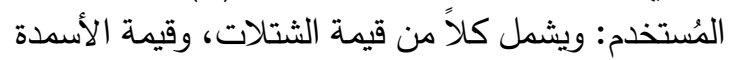

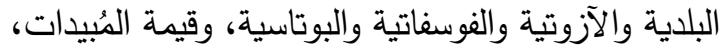

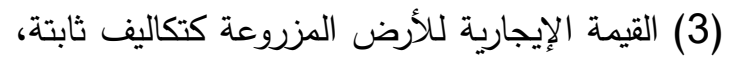
ويبين جدول 4 تكاليف وإيرادات الطماطم الصيفي بالعينة البحثية وذلك كما يلي: - اليف 
ثالثاً: المُؤثرات الاقتصادية للطماطم الصيفي بالعينة البحثية بقياس بعض المُؤشرات الاقتصادية للطماطم الصيفي بالعينة البحثية والتي تقيس الكفاءة الكُليه لها والمُتمثلة

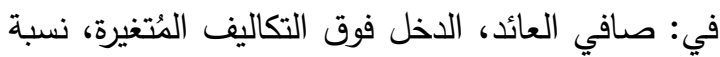
الإيرادات إلى التكاليف، وأربحية الجنيه المُنفق، يتبين من

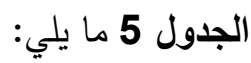
جدول 5. المُؤشرات الاقتصادية لفدان الطماطم الصيفي بالعينة البحثية خلا موسم 2020م

\begin{tabular}{|c|c|}
\hline القيمة & المُؤشررات" \\
\hline 12.52 & صافي العائد الفداني \\
\hline 16.99 & الدخل فوق التكاليف المُتغيرة \\
\hline 1.41 & نسبة الإيرادات إلى التكاليف \\
\hline 0.41 & أربحية الجنيه المئنفق \\
\hline
\end{tabular}

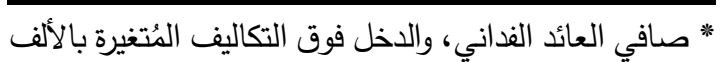

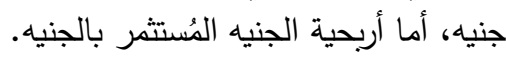
المصدر: جُمِعتُ وحُبِبتْ من جدول 4. (أ) صافي العائد الفداني: ويُُكن حسابه من خلال طرح

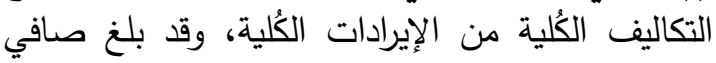

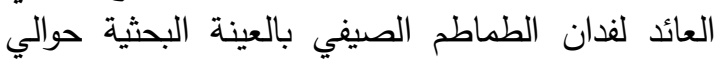
12,52 ألف جُنيهاً.

(ب) الاخل فوق التكاليف المُتغيرة: ويُمكن حسابه من

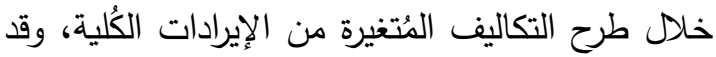

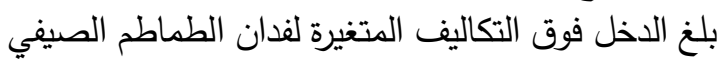
بالعينة البحثية قرابة 17 ألف جُنيهاً.

(ج) نسبة الإيرادات إلى التكاليف: ويُُكن حسابها من

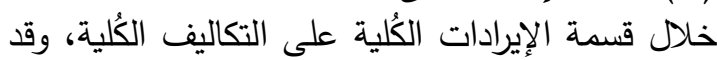
بلغت نسبة الإيرادات إلى التكاليف لفدان الطماطم الصيفي بالعينة البحثية نحو 1,41.

(د) أربحية الجنيه المُنفق: ويُككن حسابها من خلال

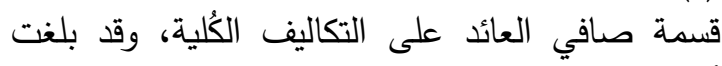
أربحية الجنية المُنفق لفدان الطماطم الصيفي حوالي 0,41 جُنيهاً.
ألف جُنيهاً/ فدان بنسبة تُمثل نحو 85,38\% من الَّان التكاليف الكُلية لإنتاج الطماطم الصيفي. جدول 4. دتوسطات تكاليف وإيرادات الطماطم الصيفي بالعينة البحثية خلال موسم 2020م.

\begin{tabular}{|c|c|c|}
\hline$\%$ & القيمة & الاقتصادية" المُتغيرات \\
\hline 18.80 & 5756.67 & أُجور العماله \\
\hline 66.58 & 20387.00 & التكاليف \\
\hline 85.38 & 26143.67 & المُتغيرة \\
\hline 14.62 & 4476.67 & الإيجار \\
\hline 100.00 & 30620.34 & التكاليف الكُلية \\
\hline- & 23.9 & كمية الناتج \\
\hline- & 1805 & \\
\hline- & 43140 & إجمالي الإيراد \\
\hline
\end{tabular}

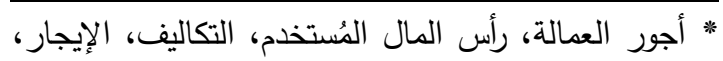

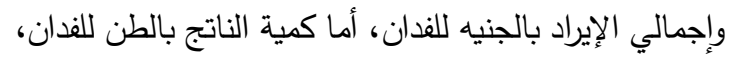
وسعر الناتج بالجنيه للطن.

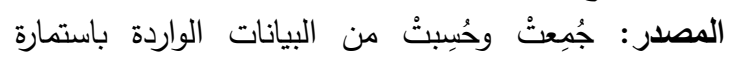
الاستبيان.

(د) الإيجار : بلغ متوسط الإيجار (تكلفة الفُرصة البديلة)

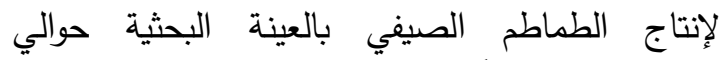

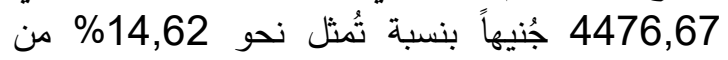
التكاليف الكُلية لإنتاج الطماطم الصيفي. (هـ) التكاليف الكُلية: بلغ مُتوسط التكاليف الكُلية لإنتاج

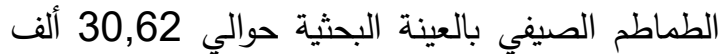
جُنيهاً/ فدان. (و) كمية الناتج: بلغ مُتوسط الكمية المُنتجة من من فئن

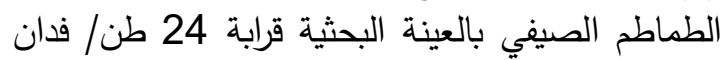
بقيمة نقدية بلغت حوالي 43,14 ألف جُنيهاً. 
وقد بلغ عدد المزارع غير الكُؤة حجمياً (24) مزرعة

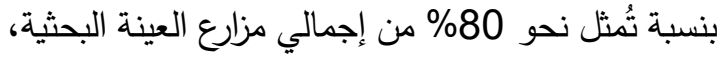

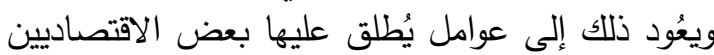

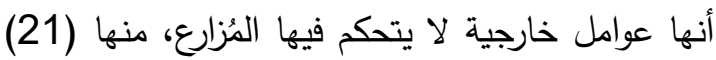

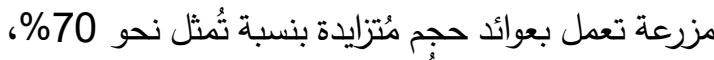

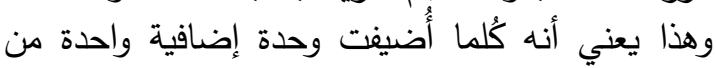

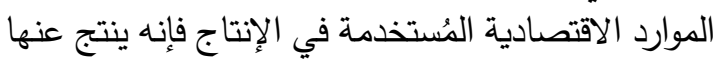

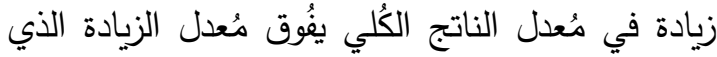

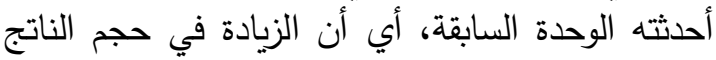

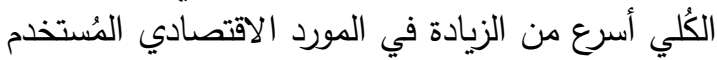

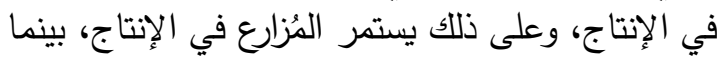

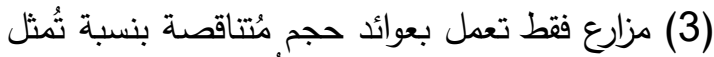

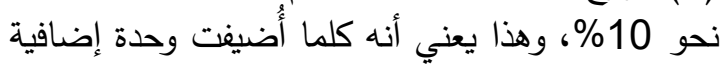

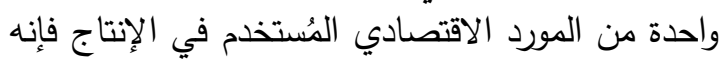

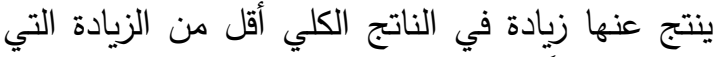

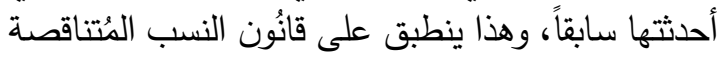

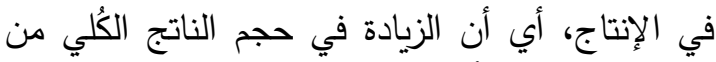

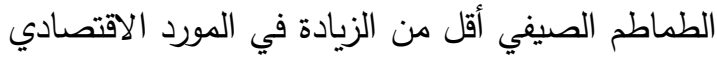

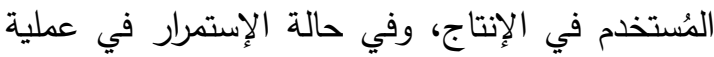

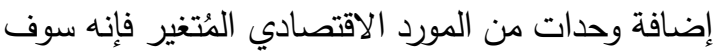

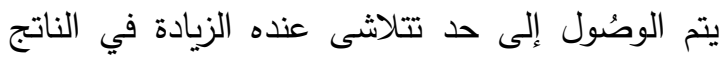
الكُلي، وبالتالي لا يستطيع المُزارع التوسع في نشاطه.

\section{2- 2 الكفاءة التقنية}

الكفاءة التقنية هي الأساس في حساب الكفاء الكفاءة

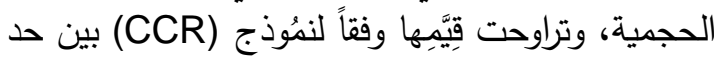

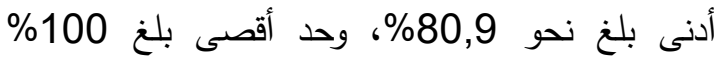

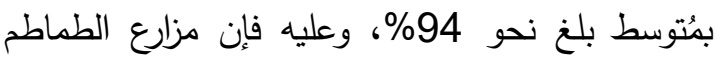

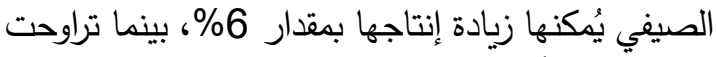

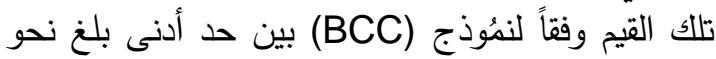

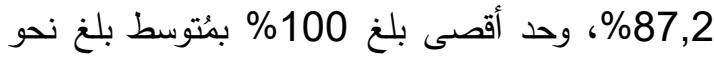

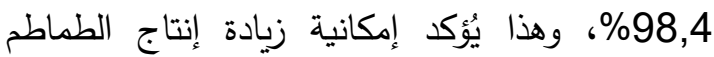

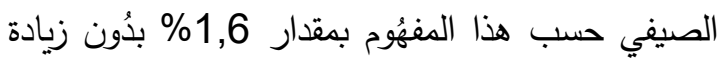

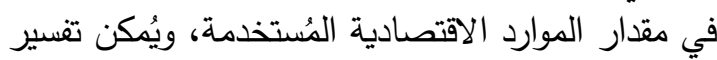

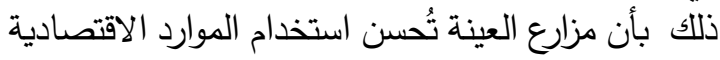

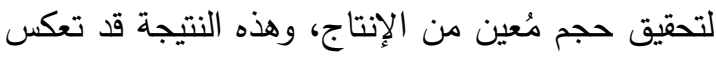
الواقع، حيث فاقت نظيرتها في ظل ثبات غلة وهلة الحجم.
رابعاً: الكفاءة الحجمية للطماطم الصيفي باستخدام نمُوذج (BCC-I) يتطلب قياس الكفاءة الحجمية لمزارع العينة البحثية قياس الكفاءة التقنية وفقاً لنمُوذجي (CCR-I) و - (BCC)

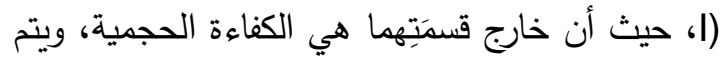

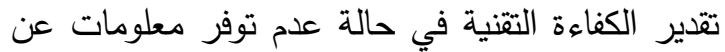

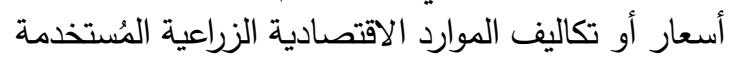

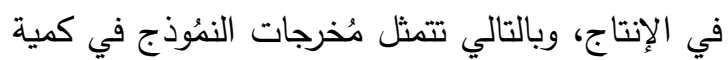

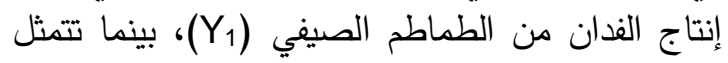

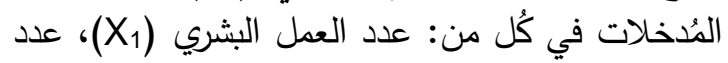

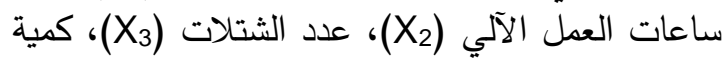

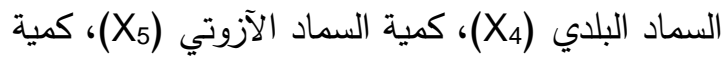

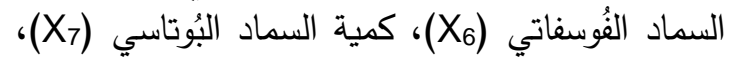
وكمية المبيدات (X) (X).

ويُبين جدول 6 درجات الكفاءة الحجمية والتقنية

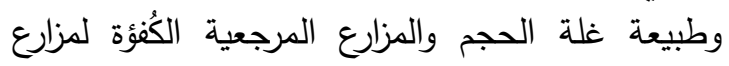
الطماطم الصيفي غير الكؤة بالعينة البحثية، ويُمكن

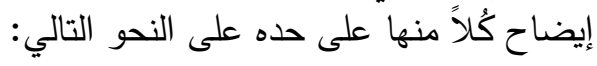

\section{1- الكفاءة الحجمية}

تراوحت قيم الكفاءة الحجمية بين حد أدنى بلغ نحو

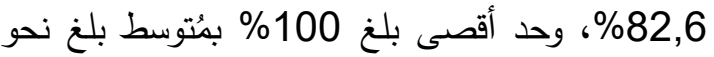

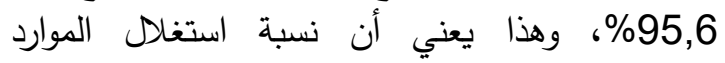

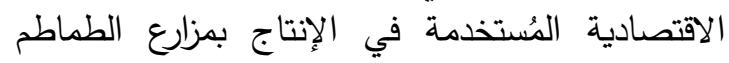
الصيفي بالعينة البحثية بلغت نحو 95,6\%ة الإنتاج برارع مما يشير إلى أنه توجد إمكانية للتُّع بنسبة 4,4\% للغئس

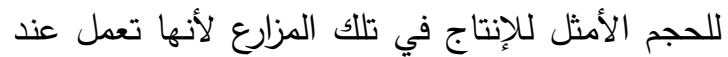
مُستوى 95,6\% من الحجم الأمثل للإنتاج.

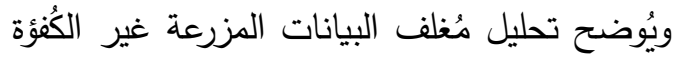

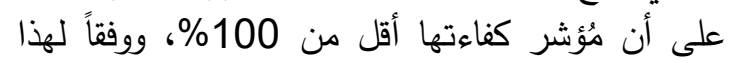
المُؤشر فإن عدد مزارع الطماطم الصيفي بالعينة البحثية

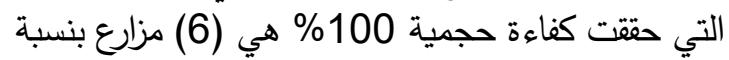
تُمثل نحو 20\% من إجمالي العينة البحثية، وهذا يعني

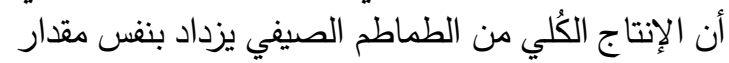

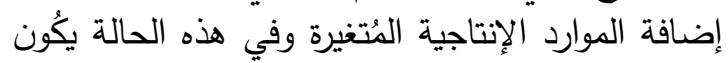

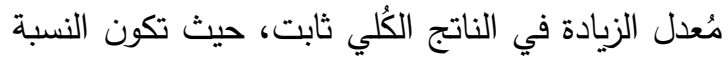

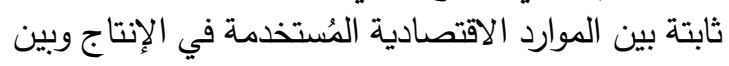
حجم الناتج من الطماطم الصيفي، وعلى هذا فإنان غلة الطئة الحجم لديها ثابتة. 
جدول 6. درجات الكفاءة الحجمية والتقنية وطبيعة غلة الحجم والمزارع المرجعية الكُفؤة لمزارع الطماطم الصيفي غير

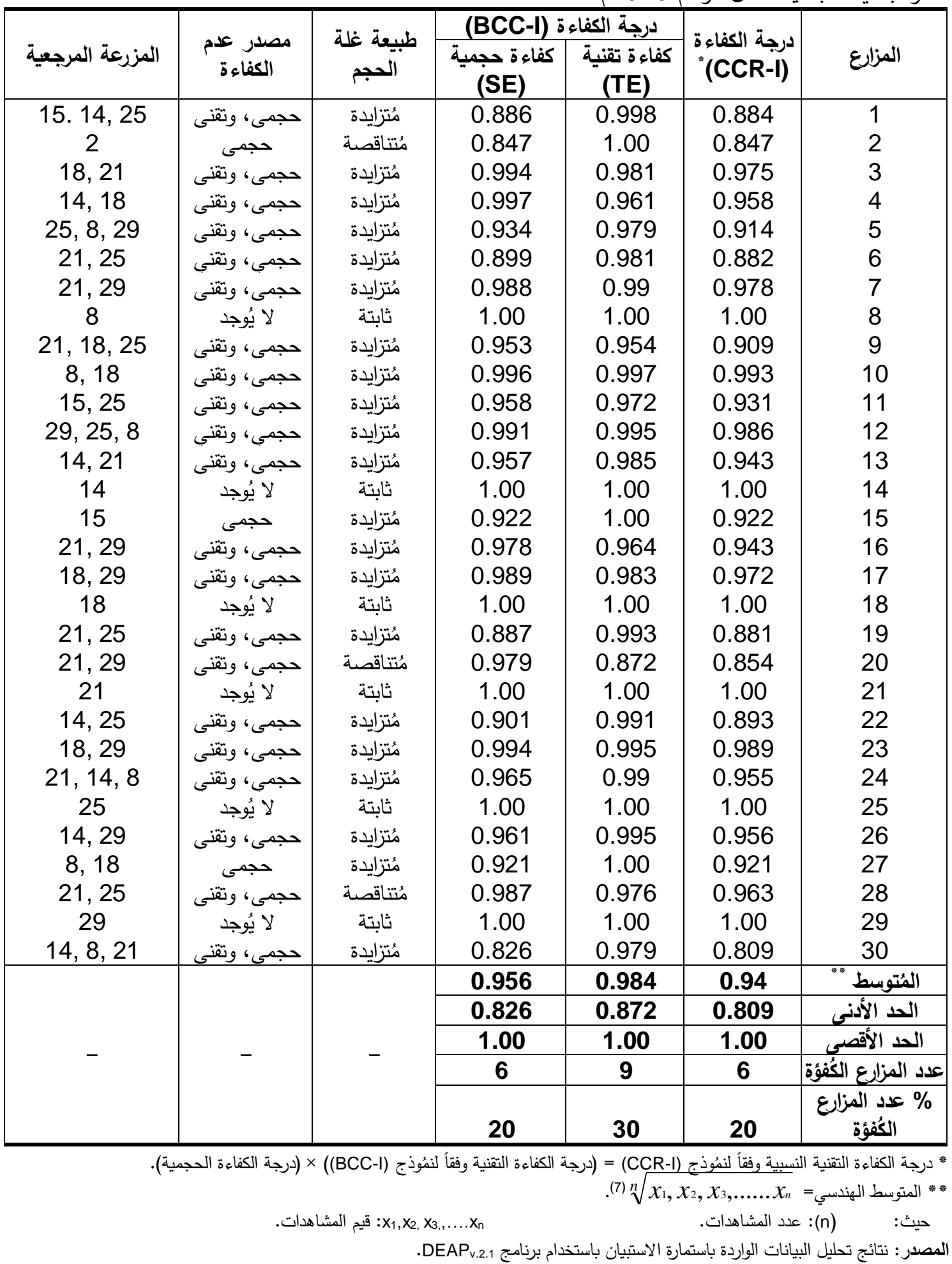


وكنلك نسبة التحسين المطلوبة لتلك المزارع، وقد تم

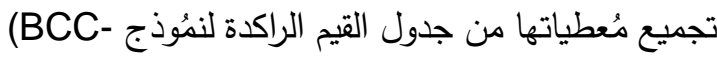

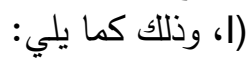
بلغ عدد المزارع التي حققت فوائض في الموارد

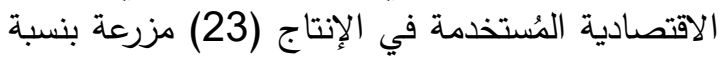

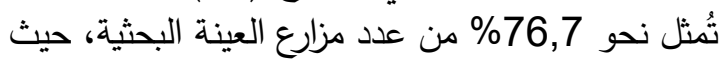

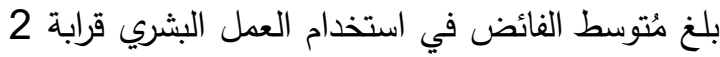

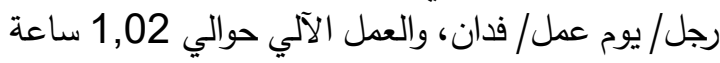
عمل آلي/ فدان، والثتلات قرابة 218 شتلة/ فدان، الأل

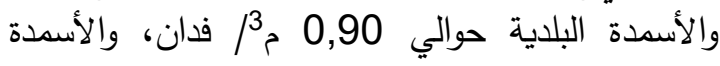
الآرُوتية حوالي 8,17 كجم وحدة فعالة/ فدان، والأسمدة كُاني

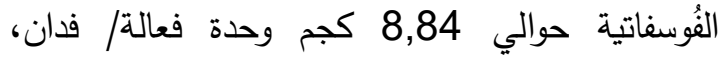

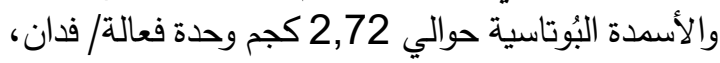
والمُبيدات حوالي 0,64 لتر / فدان، مما يشير إلى ألى أنه

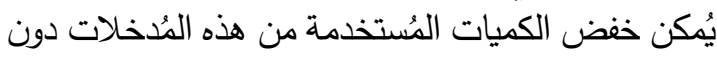
أن يتأثر مستوى الإنتاج. ويُمكن للمزارع غير الكُؤَّة تحقيق الكفاءة التتنية التامة

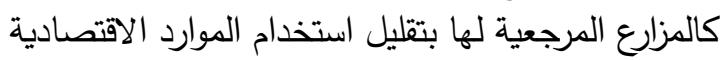

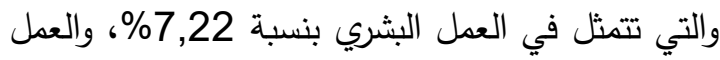

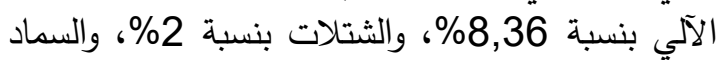

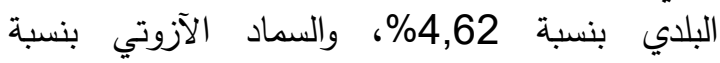
4,39\%، والسماد الفوسفاتي بنسبة 4,93\%ة 4,96، والسماد

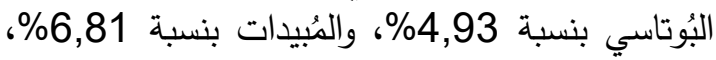
مع الإبقاء على نفس حجم الناتج من الطماطم الصيفي

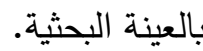

سادساً: كفاءة التكاليف لمزارع الطماطم الصيفي باستخدام نمُوذج (BCC-I)

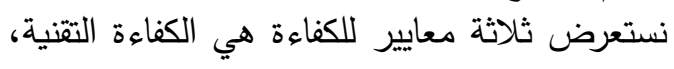

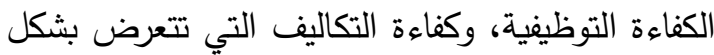

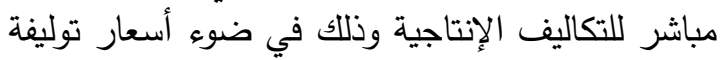

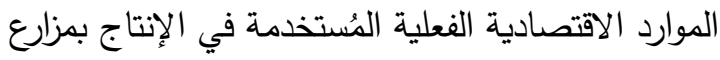

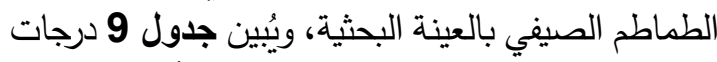

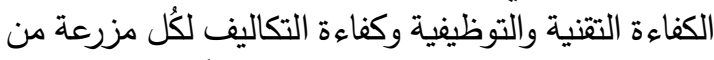

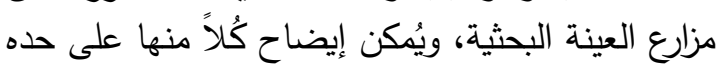

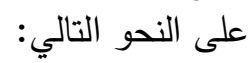

وتبين أن عدد المزارع التي حققت كفاءه تقنية تامة

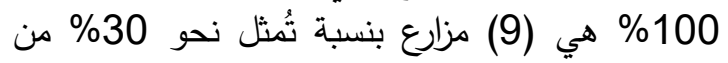
إجمالي مزارع العينة البحثية، وهي التي ثُشكل الحدود

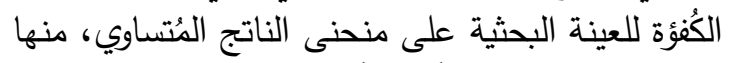

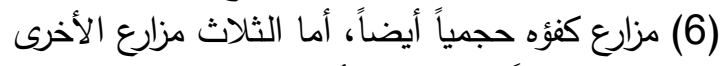

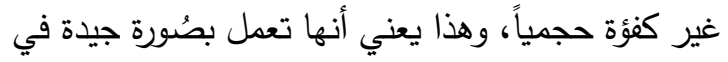

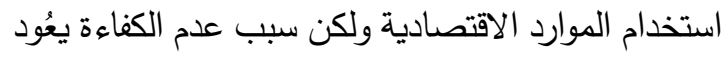

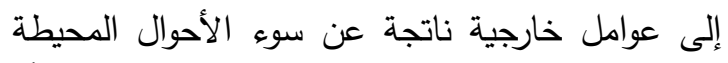

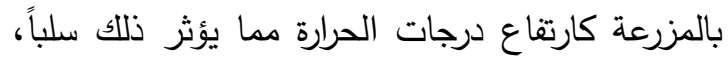

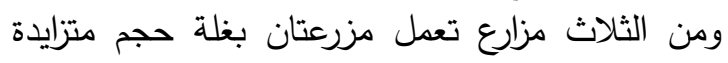

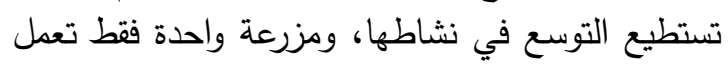

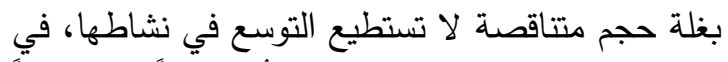
حين بلغ عدد المزارع التي ليست كُؤوَة تقنياً ولا حجمياً

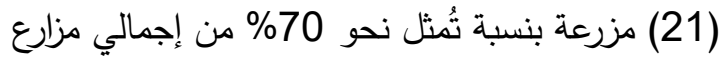
العينة البحثية، مما يتضح وجود إهدار كبير في الموارد الاقتصادية المُستخدمة وفائض في أعداد بـاد بعض العرارد

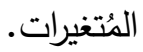

(3) المزارع المرجعية للمزارع غير الكُفؤة

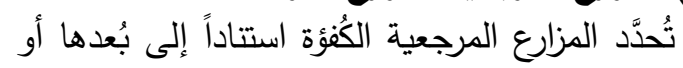

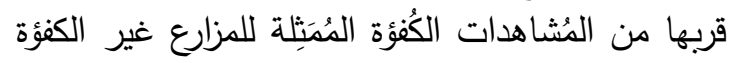

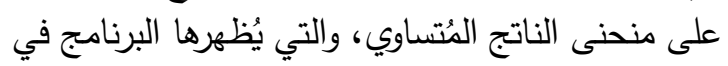

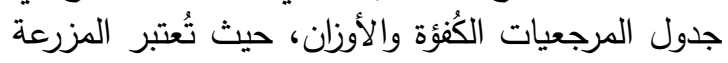

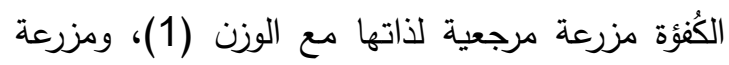

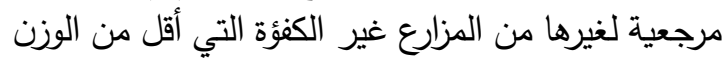

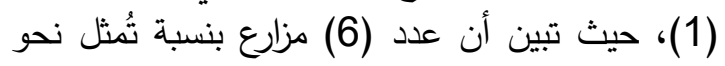

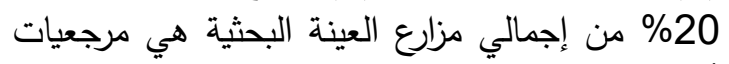

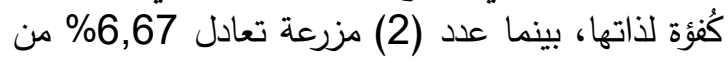

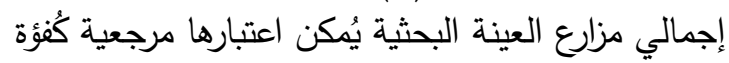

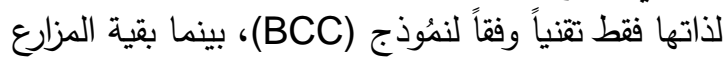
فهي مرجعية لغيرها من المزارع الأقل كفاءة.

خامساً: فوائض كميات الموارد الاقتصادية المُستخدمة

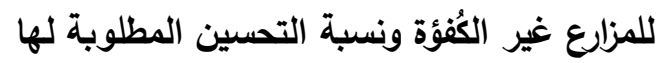

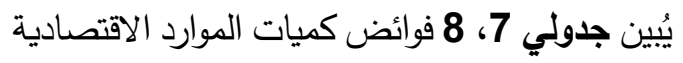

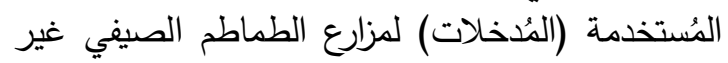
الكُؤة والتي يُكن خفضهها دُون أن يتأثر مُستوى الإنتاج، 
جدول 7. فوائض كميات الموارد الاقتصادية اليُستخدمة لمزارع إنتاج الطماطم الصيفي غير الكُؤة بالعينة البحثية خلال موسم 2020م

\begin{tabular}{|c|c|c|c|c|c|c|c|c|}
\hline \multicolumn{8}{|c|}{ فوائض كميات الموارد المَّتخدمة } & \multirow{3}{*}{ 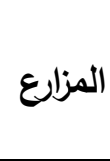 } \\
\hline \multirow[b]{2}{*}{ المبيدات } & \multicolumn{4}{|c|}{ 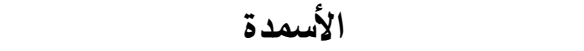 } & \multirow[b]{2}{*}{ الشتلات } & \multirow{2}{*}{ الآلمي } & \multirow{2}{*}{ البشري } & \\
\hline & البوتاسية & الفوسفاتية & 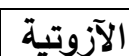 & 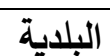 & & & & \\
\hline 0 & 0 & 9.28 & 7.96 & 2.11 & 550 & 2.36 & 4.68 & 1 \\
\hline 0 & 0 & 0 & 0 & 0 & 0 & 0 & 0 & 2 \\
\hline 1.08 & 3.26 & 0 & 0 & 0 & 0 & 1.89 & 3.39 & 3 \\
\hline 1.36 & 6.25 & 0 & 0 & 0 & 0 & 0 & 4.66 & 4 \\
\hline 0 & 0 & 17.58 & 13.22 & 2.27 & 685 & 1.99 & 3.75 & 5 \\
\hline 0.64 & 0 & 15.25 & 52.19 & 2.01 & 1190.36 & 1.19 & 3.04 & 6 \\
\hline 0 & 15.79 & 0 & 0 & 0 & 0 & 0 & 5 & 7 \\
\hline 0 & 0 & 0 & 0 & 0 & 0 & 0 & 0 & 8 \\
\hline 1.87 & 19.83 & 0 & 0 & 0 & 0 & 0.53 & 3.24 & 9 \\
\hline 0.46 & 0 & 0 & 0 & 2.19 & 732 & 2.39 & 3.98 & 10 \\
\hline 0 & 0 & 0 & 0 & 1.89 & 330 & 1.98 & 3.72 & 11 \\
\hline 0.255 & 0 & 4.06 & 4.49 & 0.46 & 292.3 & 0.77 & 4.22 & 12 \\
\hline 0 & 8.03 & 0 & 0 & 0 & 0 & 2.15 & 3.98 & 13 \\
\hline 0 & 0 & 0 & 0 & 0 & 0 & 0 & 0 & 14 \\
\hline 6.31 & 0 & 75.04 & 11.42 & 0.71 & 446.59 & 0.48 & 1.12 & 15 \\
\hline 1.28 & 5.69 & 0 & 0 & 0 & 0 & 1.64 & 3.95 & 16 \\
\hline 0 & 0 & 35.28 & 11.22 & 2.3 & 0 & 0 & 0 & 17 \\
\hline 0 & 0 & 0 & 0 & 0 & 0 & 0 & 0 & 18 \\
\hline 1.08 & 1.56 & 0 & 0 & 0 & 0 & 1.65 & 3.85 & 19 \\
\hline 3.04 & 5.96 & 9.08 & 43.25 & 2.31 & 0 & 0 & 0 & 20 \\
\hline 0 & 0 & 0 & 0 & 0 & 0 & 0 & 0 & 21 \\
\hline 0 & 0 & 5.13 & 13.01 & 1.69 & 1090 & 1.77 & 4.65 & 22 \\
\hline 0.52 & 0 & 9.22 & 11.59 & 2.21 & 0 & 0 & 0 & 23 \\
\hline 0.08 & 1.36 & 7.29 & 0 & 1.77 & 0 & 2.44 & 0 & 24 \\
\hline 0 & 0 & 0 & 0 & 0 & 0 & 0 & 0 & 25 \\
\hline 0 & 0 & 5.68 & 8.07 & 1.89 & 650 & 2.3 & 4.99 & 26 \\
\hline 1.09 & 0 & 67.97 & 58.86 & 1.07 & 559.37 & 0.64 & 1.81 & 27 \\
\hline 0 & 0 & 4.22 & 9.85 & 2.11 & 0 & 1.85 & 3.98 & 28 \\
\hline 0 & 0 & 0 & 0 & 0 & 0 & 0 & 0 & 29 \\
\hline 0 & 13.86 & 0 & 0 & 0.01 & 0 & 2.51 & 1.58 & 30 \\
\hline 0.64 & 2.72 & 8.84 & 8.17 & 0.9 & 217.52 & 1.02 & 2.32 & المهتْوسط \\
\hline
\end{tabular}

المصدر: نتائج تحليل البيانات الواردة باستمارة الاستبيان باستخدام برنامج 
جدول 8. نسبة التحسين المطلوبة ليُدخلات مزارع الطماطم الصيفي بالعينة البحثية خلال موسم 2020م

\begin{tabular}{|c|c|c|c|c|c|}
\hline نسبة التحسين & التطلين & المُستهيمة القية & الفعلية & الوحدة & المُدخلات \\
\hline 7.22 & 2.32 & 29.81 & 32.13 & رجل/ يوم عمل/ & العمل البشري \\
\hline 8.36 & 1.02 & 11.18 & 12.20 & ساعة عمل| فدان & العمل الآلي \\
\hline 2.00 & 217.52 & 10632.48 & 10850 & شتلة/ فدان & الشتلات \\
\hline 4.62 & 0.90 & 18.57 & 19,47 & مم/ فدان & السماد البلدي \\
\hline 4.39 & 8.17 & 177.76 & 185.93 & وحدة فعالة/ فدان & السماد الآزوتي \\
\hline 4.96 & 8.84 & 169.38 & 178.22 & وحدة فعالة/ فدان & السماد الفوسفاتي \\
\hline 4.93 & 2.72 & 52.48 & 55.20 & وحدة فعالة/ فدان & السماد البُوتاسي \\
\hline 6.81 & 0.64 & 8.76 & 9.40 & لتر / فدان & المُبيدات \\
\hline
\end{tabular}

وبلغ عدد المزارع التي حقتت الكفاءة التوظيفية التامة

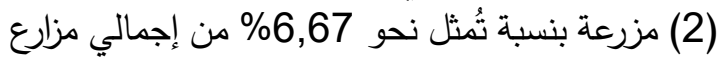

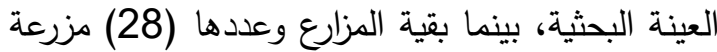

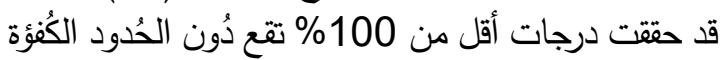
لخط التكاليف المُتساوي بحسب درجة كُل مزرعة. في حين بلغ عدد المزارع التي حققت كفاءة تقنية تامة دزية

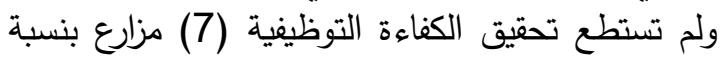

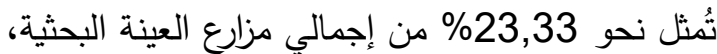

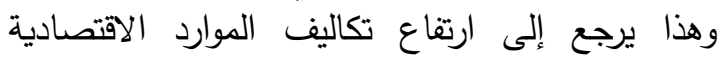

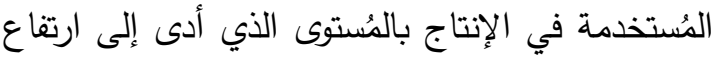

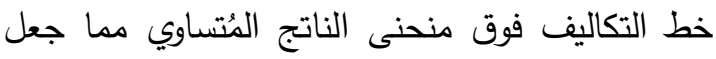

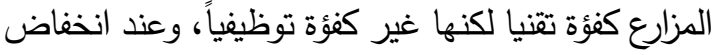

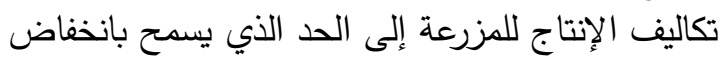

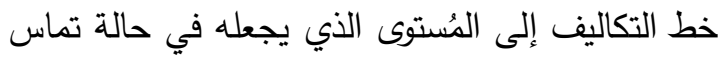

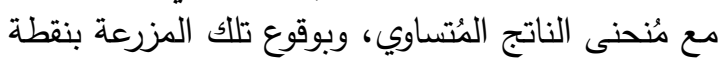

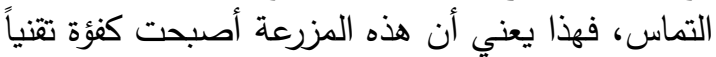

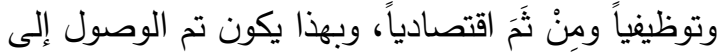

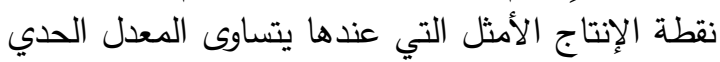
للإحلال مع النسبة السعرية وهو شرط تحقيق كفاءة الإن

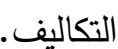

(1) الكفاءة التقنية بلغ متوسط الكفاءة التقنية نحو 98,4\% وهي ذاء ذات النتيجة التي تم التطرق إليها في ظل تغير غلة الحجم

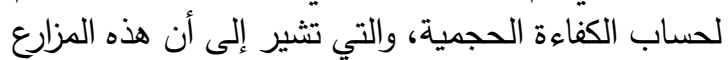

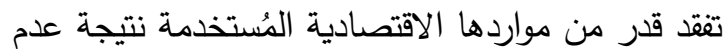

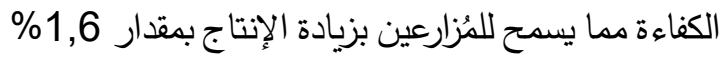

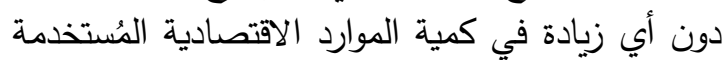
في الإنتاج، وقد تم الإستعانة بالكفاءة التقنية مرة أخرى في حساب كفاءة التكاليف.

(2) الكفاءة التوظيفية تراوحت درجات الكفاءة التوظيفية لمزارع الطماطم

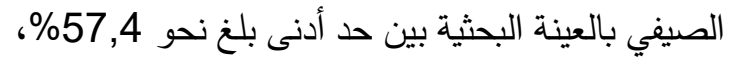

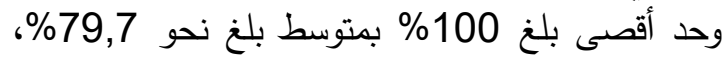
وهذا يعني أن إعادة توظيف أو توليف المواعت الموارد الاقتصادية

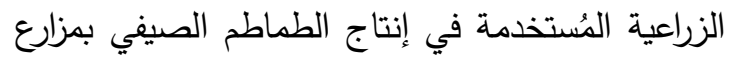

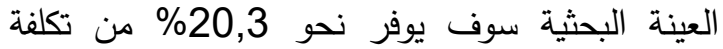

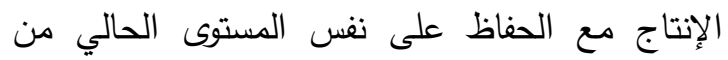

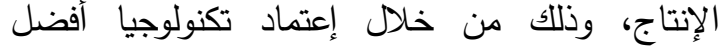
وتوظيف (تخصيص) أمثل للموارد. 
(3) كفاءة التكاليف تراوحت درجات كفاءة التكاليف أو الكفاءة الاقتصادية لمزارع الطماطم الصيفي بالعينة البحثية بين

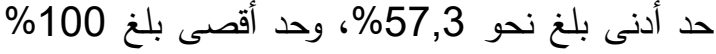

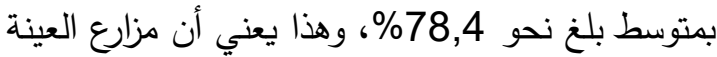

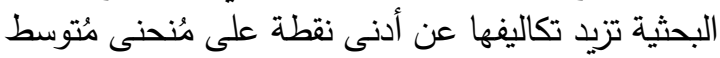

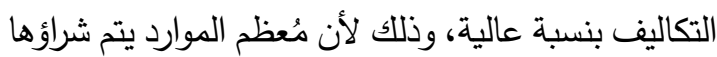

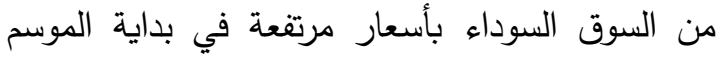

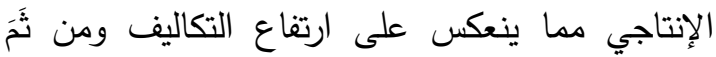

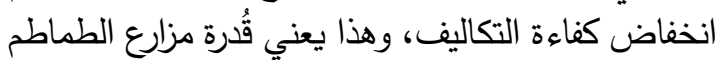

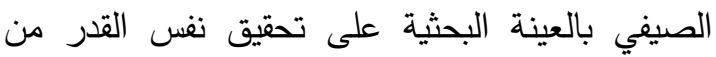
الإنتاج في ظل خفض النف التكاليف الإنتاجية بنسبة \%21,6 أي أنها تستطيع تحقيق نفس القدر من الإنتاج

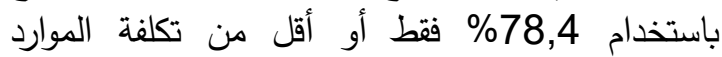
المُستخدمة حتى تُصبح كُفؤة اقتصادياً.

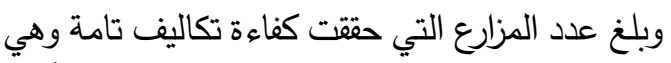

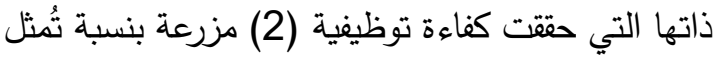
نحو 6,67\% من إجمالي مزارع العينة البحثية، بينما

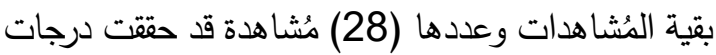
أقل من 100\%، ويُشير ذلك إلى انخفاض مُستويات كفاءة التكاليف نتيجة انخفاض الكفاءة التوظيفية.

سابعاً: الآثار الاقتصادية المُترتبة على تحقيق الكفاءة التقنية في إنتاج الطماطم الصيفي الصائة الصنرتية

(1) على مُستوى العينة البحثية

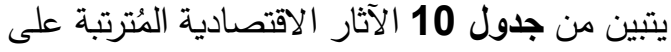

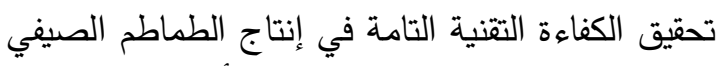

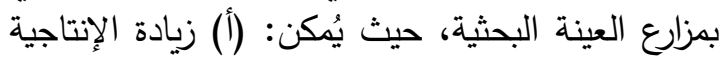

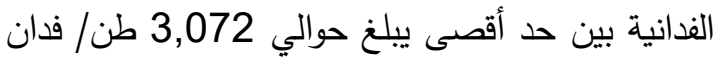
بقيمة نقدية قُدِرَتْ بحوالي رقم (20)، وحد أدنى يبلغ حوالي

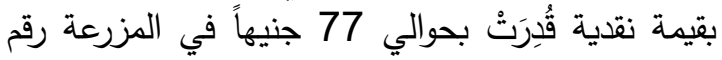
(1)، بمتوسط إنتاجية يبلغ حوالي 0,372 طن/ فدان

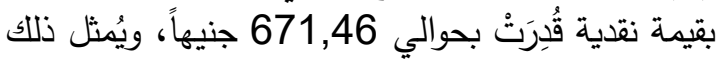
زيادة في كل من إجمالي وصافي العائد الفداني لأن

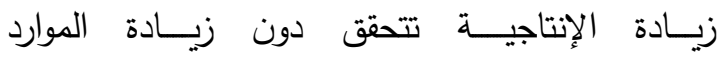
الاقتصادية المُستخدمة في الإنتاج، (ب) زئادية لديادة إنتاج

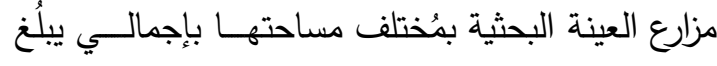

جدول 9. درجات الكفاءة التقنية والتوظيفية وكفاءة التكاليف لمزارع الطماطم الصيفي بالعينة البحثية خلال

\begin{tabular}{|c|c|c|c|}
\hline 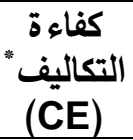 & 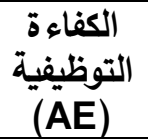 & $\begin{array}{l}\text { التقفنية } \\
\text { (TE) } \\
\text { (TE) }\end{array}$ & المزارع \\
\hline 0.573 & 0.574 & 0.998 & 1 \\
\hline 1.00 & 1.00 & 1.00 & 2 \\
\hline 0.644 & 0.656 & 0.981 & 3 \\
\hline 0.841 & 0.875 & 0.961 & 4 \\
\hline 0.792 & 0.809 & 0.979 & 5 \\
\hline 0.606 & 0.618 & 0.981 & 6 \\
\hline 0.71 & 0.717 & 0.99 & 7 \\
\hline 1.00 & 1.00 & 1.00 & 8 \\
\hline 0.636 & 0.667 & 0.954 & 9 \\
\hline 0.75 & 0.752 & 0.997 & 10 \\
\hline 0.78 & 0.802 & 0.972 & 11 \\
\hline 0.727 & 0.731 & 0.995 & 12 \\
\hline 0.954 & 0.969 & 0.985 & 13 \\
\hline 0.71 & 0.71 & 1.00 & 14 \\
\hline 0.689 & 0.689 & 1.00 & 15 \\
\hline 0.938 & 0.973 & 0.964 & 16 \\
\hline 0.948 & 0.965 & 0.983 & 17 \\
\hline 0.901 & 0.901 & 1.00 & 18 \\
\hline 0.725 & 0.73 & 0.993 & 19 \\
\hline 0.655 & 0.751 & 0.872 & 20 \\
\hline 0.775 & 0.775 & 1.00 & 21 \\
\hline 0.961 & 0.97 & 0.991 & 22 \\
\hline 0.794 & 0.798 & 0.995 & 23 \\
\hline 0.944 & 0.954 & 0.99 & 24 \\
\hline 0.694 & 0.694 & 1.00 & 25 \\
\hline 0.727 & 0.731 & 0.995 & 26 \\
\hline 0.809 & 0.809 & 1.00 & 27 \\
\hline 0.732 & 0.75 & 0.976 & 28 \\
\hline 0.999 & 0.999 & 1.00 & 29 \\
\hline 0.801 & 0.818 & 0.979 & 30 \\
\hline 0.784 & 0.797 & 0.984 & المُتوسط" " \\
\hline 0.573 & 0.574 & 0.872 & الحد الأدنىى \\
\hline 1.00 & 1.00 & 1.00 & الحد الأقصىى \\
\hline 2 & 2 & 9 & عدد المُزارعة \\
\hline 6.67 & 6.67 & 30 & المزارع الكُفؤة \\
\hline
\end{tabular}

* كفاءة التكاليف = الكفاءة التقنية × الكفاءة التوظيفية

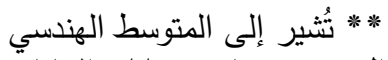
المصدر: نتائج تحليل البيانات الواردة بارئيل باستمارة الاستبيان باستخدام برنامج نقائج تحليل 
جدول 10. الآثار الاقتصادية المُترتبة على تحقيق الكفاءة التقنية التامة في إنتاج الطماطم الصيفي على مُستوى العينة البحثية خلال موسم 2020م.

\begin{tabular}{|c|c|c|c|c|c|c|c|c|}
\hline \multirow{2}{*}{ الوفر المُتحقق في الري (مُ3) } & \multirow{2}{*}{ المساحة المُقابلة } & \multirow{2}{*}{$\begin{array}{c}\text { الزيادة الممكنة في } \\
\text { الإنتاج } \\
\text { (طن) }\end{array}$} & \multirow{2}{*}{ 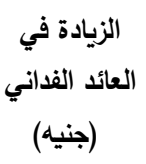 } & \multicolumn{3}{|c|}{ الإنتاجية (طن/ فدان) } & \multirow{2}{*}{ التقنية (الكفاءة } & \multirow[b]{2}{*}{ المزارع } \\
\hline & & & & 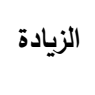 & المُستهدف & الفعلي & & \\
\hline 34.87 & 0.01 & 0.22 & 77 & 0.044 & 22.044 & 22 & 0,998 & 1 \\
\hline- & - & - & - & - & 21 & 21 & 1,00 & 2 \\
\hline 198.759 & 0.057 & 1.37 & 775.2 & 0.456 & 24.456 & 24 & 0,981 & 3 \\
\hline 407.979 & 0.117 & 2.92 & 1852.5 & 0.975 & 25.975 & 25 & 0,961 & 4 \\
\hline 366.135 & 0.105 & 2.1 & 735 & 0.42 & 20.42 & 20 & 0,979 & 5 \\
\hline 397.518 & 0.114 & 2.51 & 710.6 & 0.418 & 22.418 & 22 & 0,981 & 6 \\
\hline 139.48 & 0.04 & 0.96 & 432 & 0.24 & 24.24 & 24 & 0,990 & 7 \\
\hline- & - & - & - & - & 26 & 26 & 1,00 & 8 \\
\hline 641.608 & 0.184 & 4.23 & 2010.2 & 1.058 & 24.058 & 23 & 0,954 & 9 \\
\hline 31.383 & 0.009 & 0.21 & 124.2 & 0.069 & 23.069 & 23 & 0,997 & 10 \\
\hline 488.18 & 0.14 & 3.08 & 1170.4 & 0.616 & 22.616 & 22 & 0,972 & 11 \\
\hline 87.175 & 0.025 & 0.625 & 200 & 0.125 & 25.125 & 25 & 0,995 & 12 \\
\hline 209.22 & 0.06 & 1.5 & 637.5 & 0.375 & 25.375 & 25 & 0,985 & 13 \\
\hline- & - & - & - & - & 24 & 24 & 1,00 & 14 \\
\hline- & - & - & - & - & 23 & 23 & 1,00 & 15 \\
\hline 502.128 & 0.144 & 3.6 & 1710 & 0.9 & 25.9 & 25 & 0,964 & 16 \\
\hline 355.674 & 0.102 & 2.75 & 826.2 & 0.459 & 27.459 & 27 & 0,983 & 17 \\
\hline- & - & - & - & - & 26 & 26 & 1,00 & 18 \\
\hline 122.045 & 0.035 & 0.88 & 315 & 0.175 & 25.175 & 25 & 0,993 & 19 \\
\hline 1785.344 & 0.512 & 12.29 & 5222.4 & 3.072 & 27.072 & 24 & 0,872 & 20 \\
\hline- & - & - & - & - & 24 & 24 & 1,00 & 21 \\
\hline 62.766 & 0.018 & 0.45 & 405 & 0.225 & 25.225 & 25 & 0,991 & 22 \\
\hline 69.74 & 0.02 & 0.44 & 176 & 0.11 & 22.11 & 22 & 0,995 & 23 \\
\hline 244.09 & 0.07 & 1.68 & 408 & 0.24 & 24.24 & 24 & 0,990 & 24 \\
\hline- & - & - & - & - & 26 & 26 & 1,00 & 25 \\
\hline 69.74 & 0.02 & 0.5 & 250 & 0.125 & 25.125 & 25 & 0,995 & 26 \\
\hline- & - & - & - & - & 24 & 24 & 1,00 & 27 \\
\hline 418.44 & 0.12 & 3.12 & 1123.2 & 0.624 & 26.624 & 26 & 0,976 & 28 \\
\hline- & - & - & - & - & 26 & 26 & 1,00 & 29 \\
\hline 366.135 & 0.105 & 2.1 & 840 & 0.42 & 20.42 & 20 & 0,979 & 30 \\
\hline- & - & - & 671.46 & 0.372 & - & - & - & المتوسط \\
\hline 6998.41 & 2.007 & 47.53 & - & - & - & - & - & الإجمالي \\
\hline
\end{tabular}

المصدر: نتائج التحليل الكمي للبيانات الواردة باستمارة الاستبيان باستخدام برنامج 
نتيجة رفع الكفاءة التقنية، (ج) ترشيد استخدام مياه الري

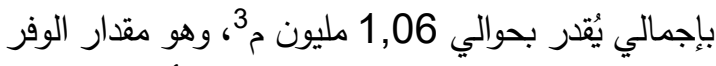

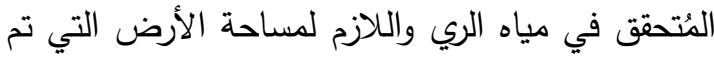

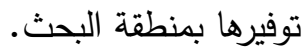

\section{(3) على مُستوى مُحافظة الإسكندرية} بتعميم النتائج المُترتبة على على تحقيق الإسكندية الكفاءة التقنية

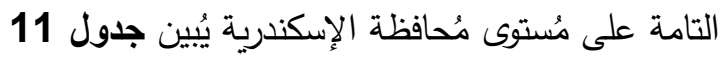

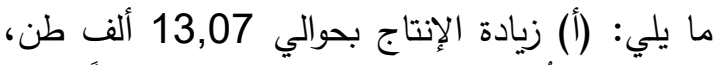
بقيمة نقدية قُدرت بحوالي 23,59 مليون جُنيهاً، (ب) الأجاج

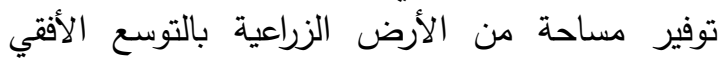

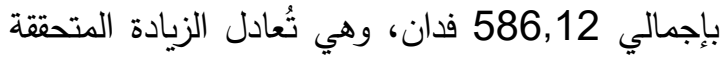
في الإنتاج نتيجة رفع الكفاءة التقنية، (ج) ترشيد استخدام

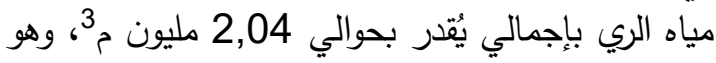

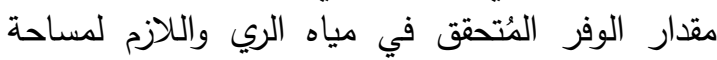
الأرض التي تم توفيرها بمُحافظة الإسكندرية.
حوالي 47,53 طناً بقيمة نقدية قُدرت بحوالي

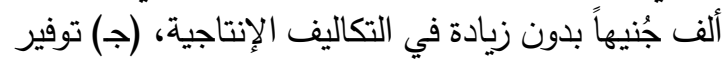

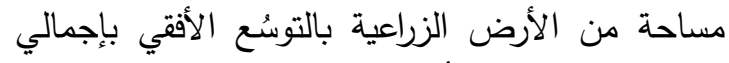

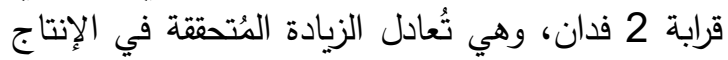
نتيجة رفع الكفاءة التقنية، (د) ترشيد استخدام مياه الري التراي

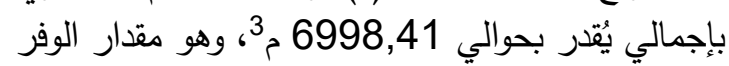

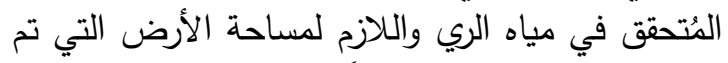

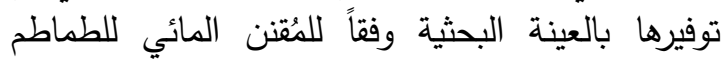
الصيفي والبالغ حوالي 3487 مُ3. (2) على مُستوى منطقة البحث

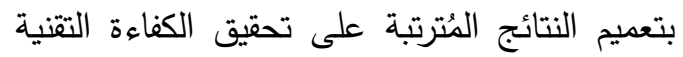

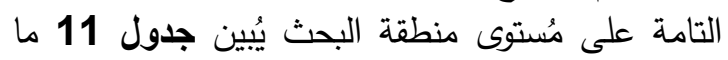

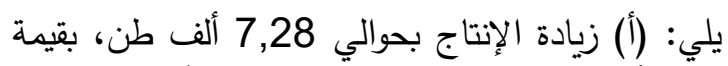

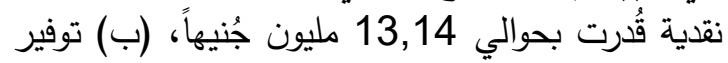
مساحة من الأرض الزراعية بالتوسُع الأفقي بإجمالي الإني

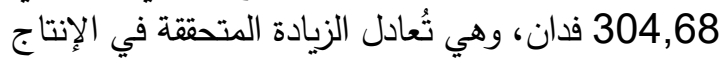

جدول 11. الآثار الاقتصادية المُترتبة على تحقيق الكفاءة التقنية التامة في إنتاج الطماطم الصيفي على مُستوى

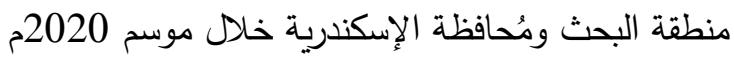

\begin{tabular}{|c|c|c|c|c|c|}
\hline الوفر المُتحقق & المساحة المُقابلة & الزيادة الممكنة & \multicolumn{2}{|c|}{ الإنتاجية (طن/ فدان) } & \multirow[b]{2}{*}{ البيان البان } \\
\hline في مياه الري & 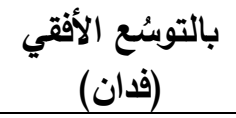 & في الإنتاج & متوسط مقدار & الإنتاجية & \\
\hline 1.06 & 304.68 & 7.28 & \multirow{2}{*}{0.372} & 23.9 & إدارة العامرية \\
\hline 2.04 & 586.12 & 13.07 & & 22.3 & الإسكندرية \\
\hline
\end{tabular}

المصدر: - جُمِعتُ وحُسببتُ من وزارة الزراعة واستصلاح الأراضي (2020م)، مُديرية الزراعة بالإسكندرية، إدارة الخدمات الزراعية والحيوانية، سجلات قسم الإحصاء، بيانات غئ وخير منشُورة. - جدولي (4)، (10). 
التوسع في نشاطها، ومزرعة واحدة تعمل بغلة حجم

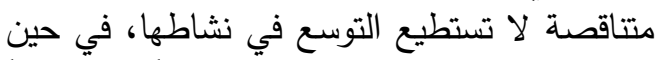
بلغ عدد المزارع التي ليست كُفؤة تقنياً ولا حجمياً

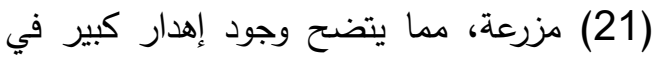

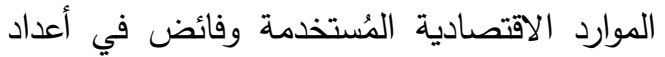

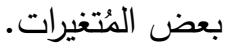

(5) يُكن للمزارع غير الكُؤُة تحقيق الكفاءة التقنية التامة

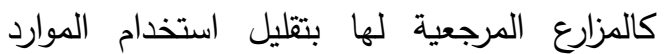

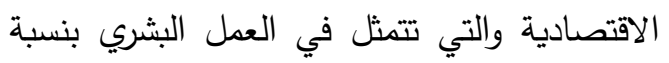

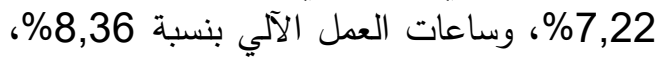
والشتلات بنسبة 2\%؛ وساعة والسماد البلدي بنسبة

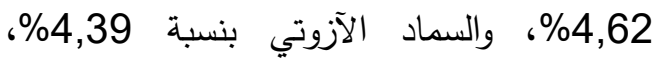

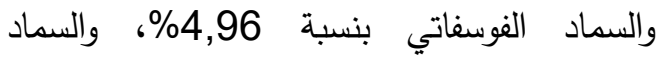

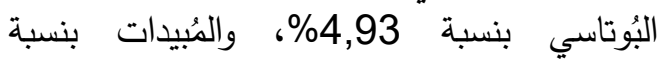

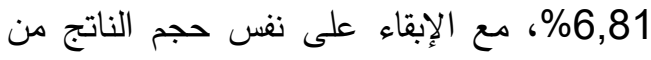
الطماطم الصيفي بالعينة البحثية. (6) بلغ مُتوسط الكفاءة التوظيفية لمزارع الطماطية الطية

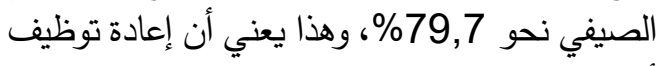

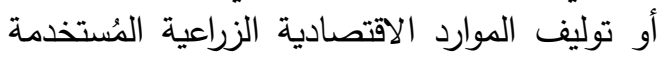
في إنتاج الطماطم الصيفي بمزارع العينة البحثية

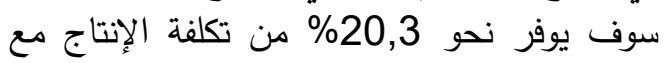

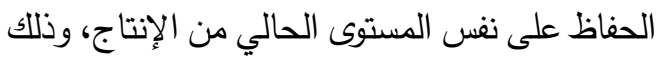

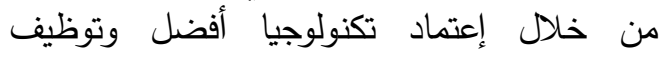
(تخصيص) أمثل للموارد، وبلغت عدد المناد المزارع التي

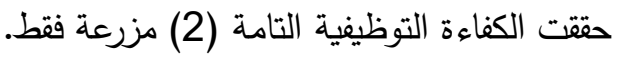

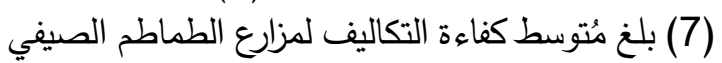

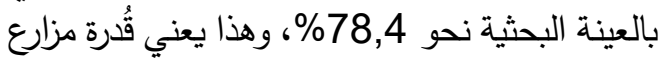
الطماطم الصيفي بالعينة البحثية على تحقيق نفي الإنس

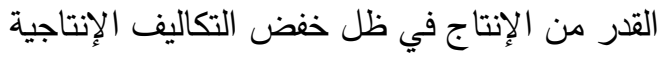
بنسبة 21,6\% من أي أنها تستطيع تحقيق نفس القدر

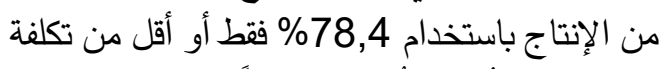

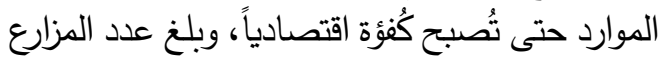
التي حققت كفاءة تكاليف تامة وهي ذاتهوة ذاتها التي

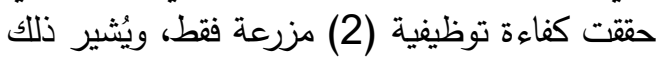
إلى انخفاض مُستويات كفاءة التكاليف نتيجة انخفاض الكفاءة التوظيفية.

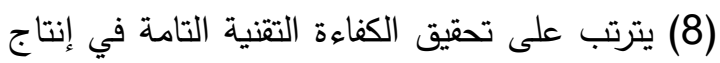

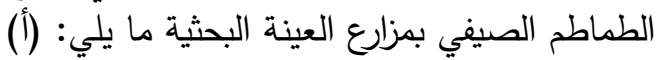
زيادة الإنتاجية الفدانية بمتوسط يبلغ حوالي

\section{النتائج البحثية}

توصل البحث إلى مجمُوعة من النتائج، ويَمكن استعراض أهمها فيما يلي (1) بلغ مُتوسط التكاليف الكُلية لإنتاج الطماطم الصيفي لئي

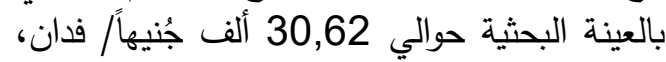

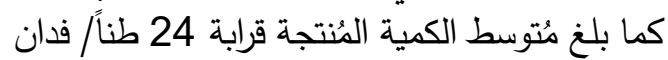

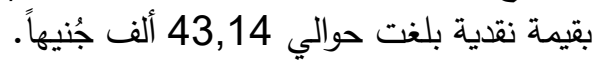
(2) بلغت معايير الكفاءة الكُلية لفدان الطماطم الصيفي بالعينة البحثية وهي: صافي العائد حوالي ألف جُنيهاً، والدخل فوق التكاليف المتغيرة قرابة 17 ألف جُنيهاً، ونسبة الإيرادات إلى فئل التكاليف نحو النيف 1,41، وأربحية الجنية الكُنفق حوالي الإني 0,41 جُنيهاً.

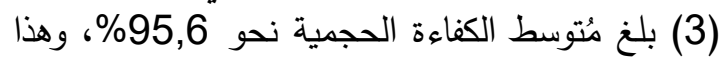
يعني أنه توجد إمكانية للتوسع بنسبة 4,4 الكنة

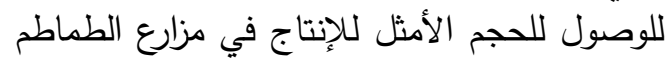

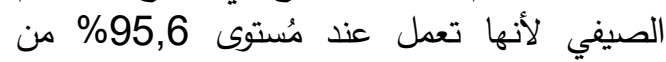
الحجم الأمثل للإنتاج، وقد بلغ عدد مزارع الطماطم

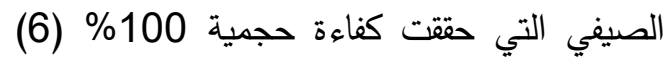
مزارع، وعلى هذا فإن غلة الحجم لديها ثابتة، كما

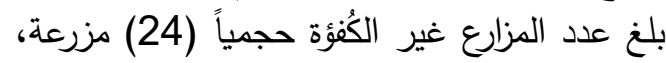

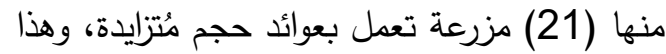

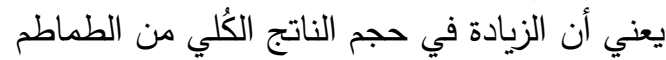

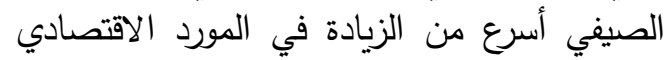

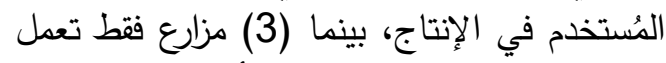

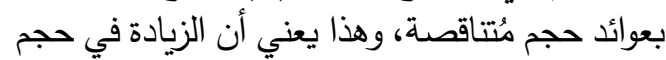

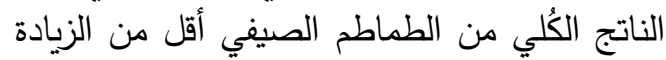
في المورد الاقتصادي المُستخدم في الإنتاج.

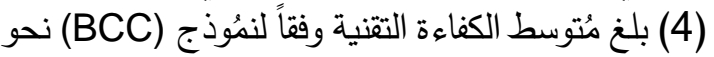

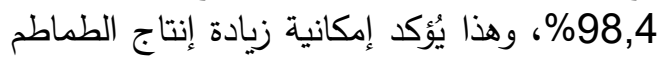

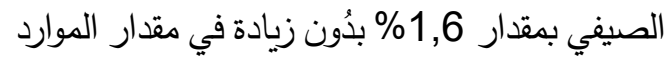

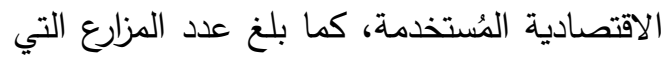

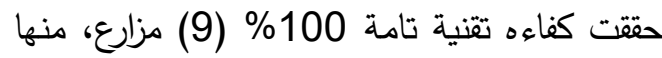

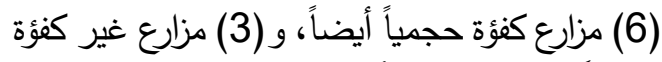

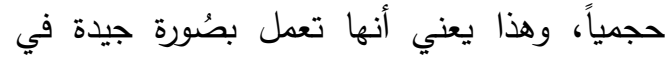
استخدام الموارد الاقتصادية، ولكن سبب عدم الكفاءة لئل

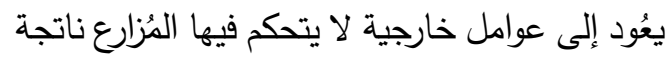

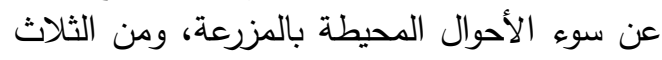

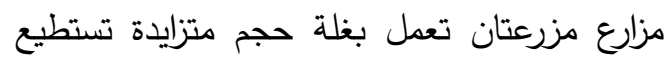




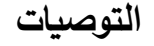

في ضوء النتائج التي توصل إليها البحث، فإنه يُوصي

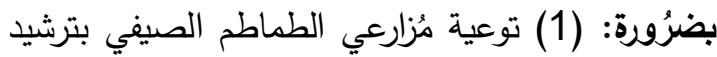

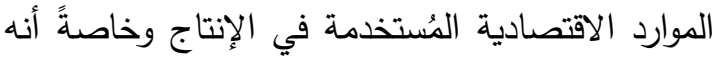

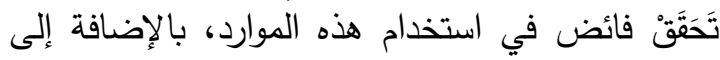

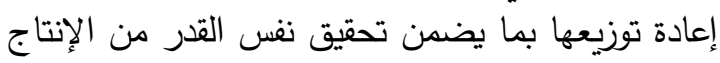

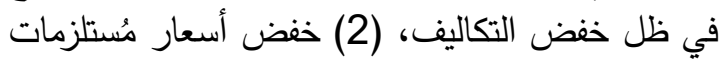

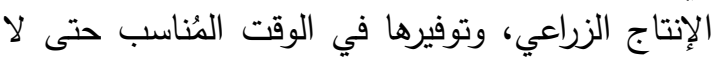

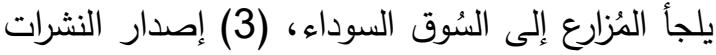

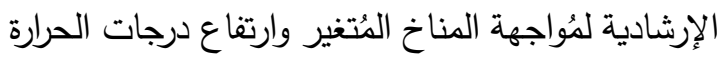
في زراعة الطماطم الصيفي.

$$
\text { المراجـع }
$$

أولاً: المراجع العربية

أبُو سعد، حسن إبراهيم نبيه، أحمد محمد فراج قاسم،

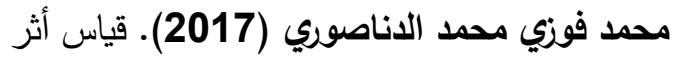

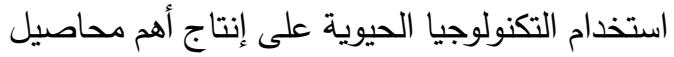

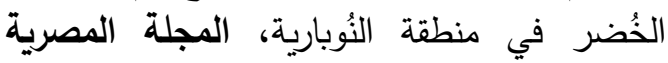
للاقتصاد الزراعي، المجلد 27، ص ص صن 1450 1415-

.1450

الجهاز المركزي للتعبئة العامة والإحصاء (A 2018).

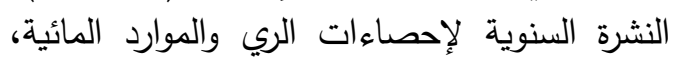

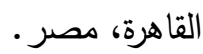
الجهاز المركزي للتعبئة العامة والإحصاء (B 2018). النشرة السنوية لإحصاءات المساحات المحضُولية الإحماء الدناصوري، محمد فوزي، محمد (2019)، الإنتاني، الكفاءة الاقتصادية والتسويقية لمحصُول الطماطو الصفي الصيفي

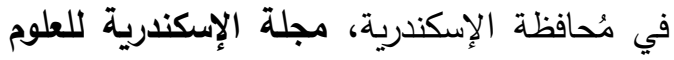
الزراعية، المُجلد 64، 379-395.
طن/ فدان بقيمة نقدية قُدِرَتْ بحوالي

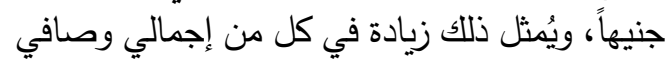

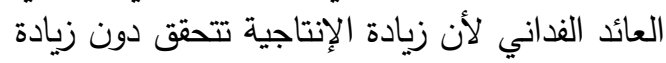

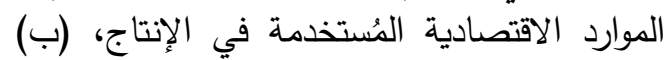

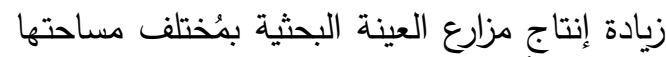

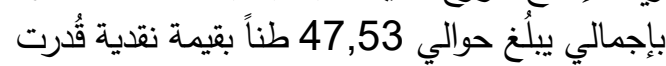

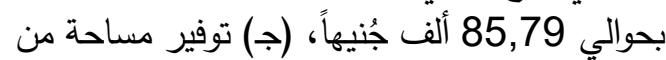

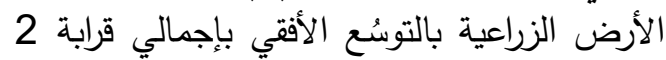

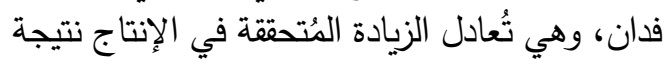

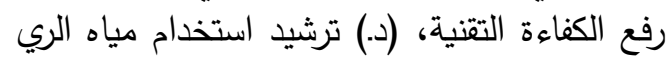

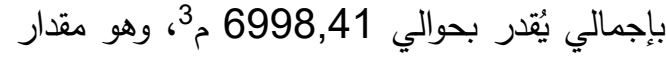

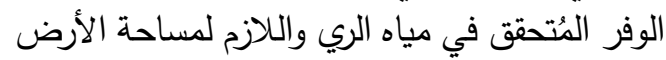
التي تم توفيرها بالعينة البحثية.

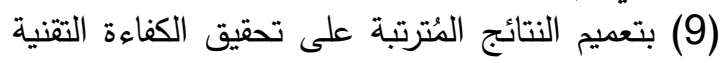

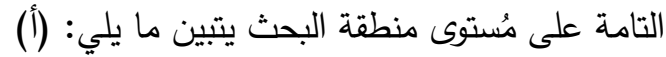

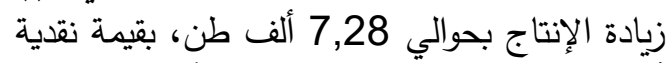

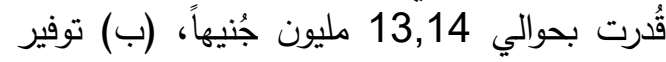
مساحة من الأرض الزراعية بالتوسُع الأفقي بإجمالي لُّاتي

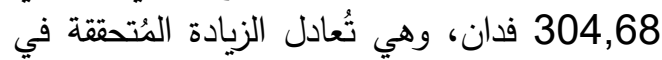

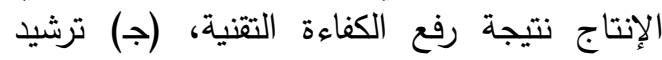

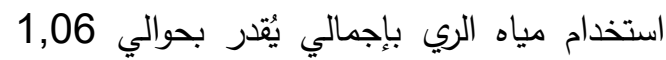

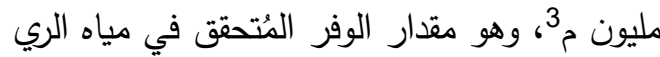
واللازم لمساحة الأرض التي تم لتر توفيرها بمنطقة

(10) بتعميم النتائج المُترتبة على تحقيق الكفاءة التقنية

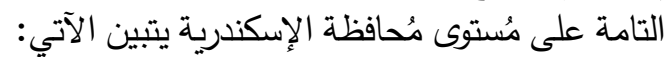

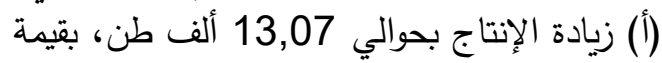

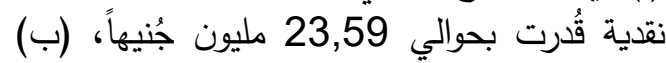
توفير مساحة من الأرض الزراعية بالتوسُع الأفقي

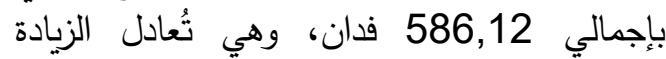

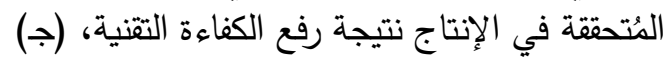

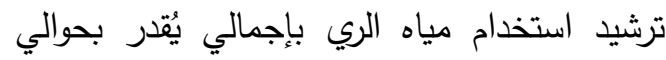

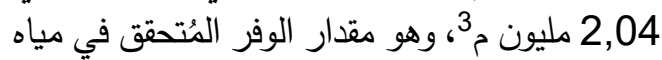
الري واللازم لمساحة الأرض التي تمثل تم توفيرها بمُحافظة الإسكندرية. 
وزارة الزراعة واستصلاح الأراضي، قطاع الثئون

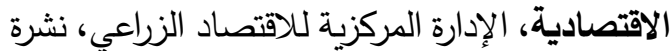

الإحصاء ات الزراعية، أعداد مُتشرقة.

وزارة الزراعة واستصلاح الأراضي (2020). مداعيرية الزيكة

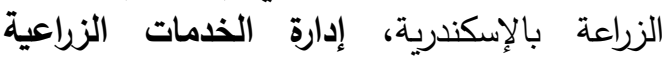

والحيوانية، سجلات قسم الإحصاء، بيانات غير الإناء الزية

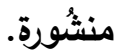

ثانياً: المراجع الأنجليزية

Banker R.D., Charnes A. and Cooper W.W. (1984). Some Models for Estimating Technical and Scale Inefficiencies in Data Envelopment Analysis, Management Science, 30, 1078-1092.

Charnes A., Cooper W.W. and Rhodes E. (1978). Measuring the Efficiency of Decision-Making Units, European J. of Operational Research, 2, 429-444.

Coelli T. (1996). A Guide to DEAP Version 2.1: A Data Envelopment Analysis (Computer) Program, CEPA Working Paper 96/8, Department of Econometrics, University of New England, Armidale, Australia, pp. 149.

Farrell M.J. (1957). The measurement of productive efficiency, $\mathbf{J}$. of the Royal Statistical Society, 120, 253- 290.

Quey J.Y. (1996). The Application of Data Envelopment Analysis in conjunction with financial ratio for bank performance in evaluation, $\mathbf{J}$. of the $\mathbf{O}$. Research Society, 47(8), 981.

Debertin D.L. (1986). Agriculture Production Economics, Univ. of Kentucky, Collier Macmillan Publishers, London, UK, pp. 183220.

Nicholson W. (1994). Intermediate Microeconomics, Amberst College, Harcourt Brace College Publishers, London, UK, pp. 92-114.
السيد، إلهام عبد المُعطي عباس (2019م). دراسة

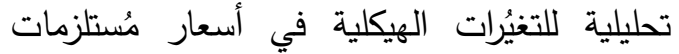
الإنتاج الزراعي في ظل المُتغيرات المحلية الراهنة

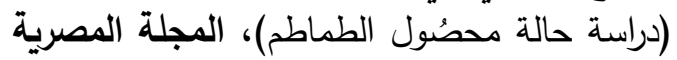

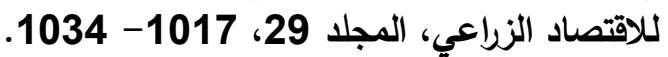

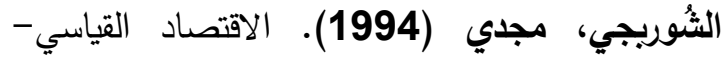

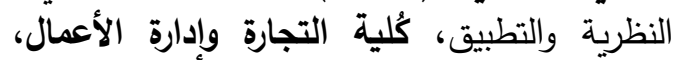
جامعة حلوان، الدار المصرية اللبنانية، الطبة الطبة الطبة

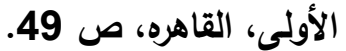

خليفة، علي يُوسف (2000). الإحصاء الإقتصادي

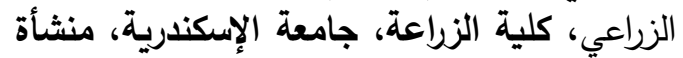

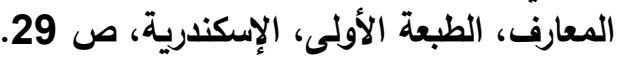

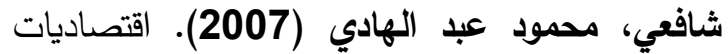
الإنتاج والتحليل الحديث للكفاءات الفنية والاقتصادية

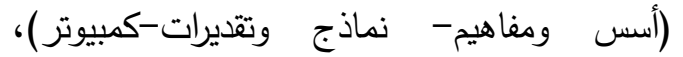
مُحاضرات لطلبة الدراسات العُليا، قسم الاقتصاد

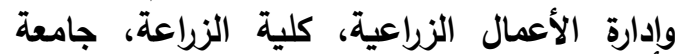
الإسكندرية، ص ص صدال 99- 116.

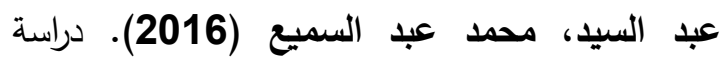
اقتصادية لإنتاج وتسويق الطماطم المصرية، رسالة

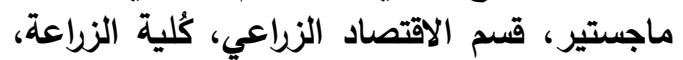

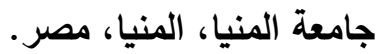
عطية، أسماء جمعة (2018). دراسة اقتصادية لإنتاج الطماطم في مصر ، رسالة ماجستير ، قسم الاقتصاد (2018

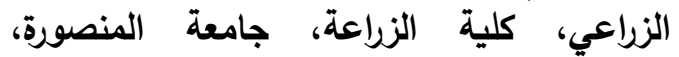
المنصورة، مصر.

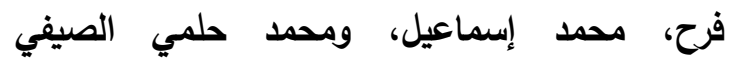

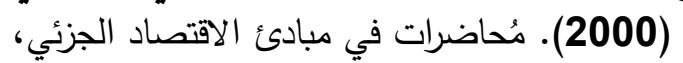

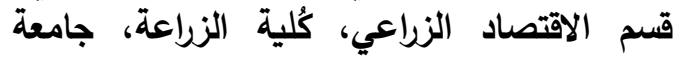

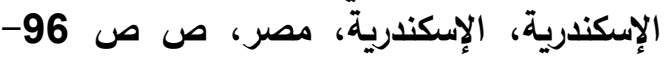
106 قاسم، أحمد فراج، ودينا محمد الثاعر (2012). أثر

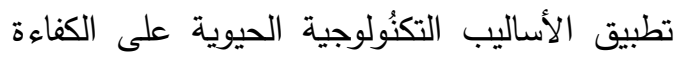

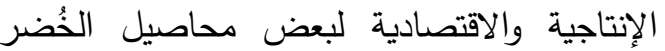

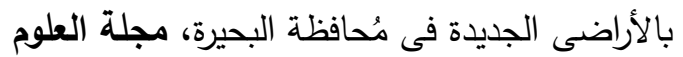
الزراعية، كلية الزراعة، جامعة المنصُورة، المجلد 253 231، 231 . هارون، على أحمد (2000). جُغرافية الزراعة، دار

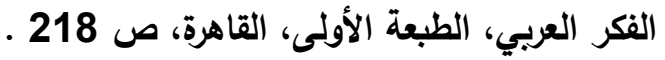




\title{
EFFICIENCY OF THE AGRICULTURAL ECONOMIC RESOURCES USED IN SUMMER TOMATO PRODUCTION IN ALEXANDRIA GOVERNORATE
}

\author{
Kassem A.M.F. ${ }^{1}$, Noura M.E. Tantawy ${ }^{1}$ and El-Santresy T.M.A. ${ }^{2^{\star}}$ \\ 1- Agricultural Economics Research Institute, Agriculture Research Center, Giza, Egypt \\ 2- Faculty of Environmental and Biological Agriculture, Beni Suef Univ., Beni Suef, Egypt \\ *Corresponding author: Dr_Tamer@agr.bsu.edu.eg \\ Received 5 September, $2020 \quad$ Accepted 26 September, 2020
}

\begin{abstract}
The research aimed to measuring the Efficiency of the Agricultural Economic Resources Used in Summer Tomato Production in Alexandria Governorate, the research is relied on using of some descriptive and quantitative economic analysis methods in data analysis, especially Data Envelopment Analysis (DEA) method, based on field data collected during the 2020 season from 30 summer tomato's farmers in Alexandria Governorate. The research reached a set of results, the most important of which can be reviewed as follows: (1) The overall efficiency criteria for a feddan of summer tomatoes in the research sample are: the net return is about 12.52 thousand pounds, the income over variable costs is about 17 thousand pounds, the benefitcosts ratio is about 1.41 , and the profit of the spent pound is about 0.41 pounds. (2) The average Scale Efficiency was about $95.6 \%$, which means that the percentage of exploitation of economic resources used in production in summer tomato farms in the research sample was about $95.6 \%$, indicating that there is a possibility of expansion of $4.4 \%$ to reach the optimum volume of production on these farms. (3) The average Technical Efficiency according to the (BCC) model is about $98.4 \%$, and this confirms the possibility of increasing the summer tomato production by $1.6 \%$ without increasing the amount of economic resources used. (4) Inefficient farms can achieve complete technical efficiency as reference farms by reducing the economic resources used, which are: the human labor by $7.22 \%$, the automated work hours by $8.36 \%$, the seedlings by $2 \%$, the fertilizer Municipal by $4.62 \%$, nitrogen fertilizer by $4.39 \%$, phosphate fertilizer by $4.96 \%$, potassium

fertilizer by $4.93 \%$, and pesticides by $6.81 \%$, while keeping the same volume of production of summer tomatoes research sample. (5) The average Allocative Efficiency of summer tomato farms was about $79.7 \%$, which means that re-employing the used economic resources will save about $20.3 \%$ of the production cost through adopting better technology and optimal employment of resources. (6) The average Cost-Efficiency of summer tomato farms in the research sample was about $78.4 \%$, which means that production costs can be reduced by about $21.6 \%$ of the current production costs without affecting the production level of summer tomatoes. (7) Achieving the technical efficiency of summer tomato production at the level of Alexandria Governorate the following: (a) Increasing production by 13.07 tons, with a monetary value estimated at 23.59 milliom pounds, (b) providing an area of agricultural land with a horizontal expansion of 586.12 feddans, which is equivalent to the increase achieved In production as a result of raising technical efficiency, (c) rationalizing the use of irrigation water in Alexandria, with a total of about 2.04 million $\mathrm{m}^{3}$, which is the amount of savings achieved in irrigation water that is necessary for the area of land that has been provided in Alexandria. In light of the findings of the research, it recommends the necessity; (1) Educating summer tomato farmers about the optimal the economic resources used in production to reach the optimum volume of production, (2) Reduce the prices of agricultural production inputs and provide them in a timely manner so that the farmer does not resort to the black market, (3) Issuing advisory bulletins to confront the changing climate and high temperatures in summer tomato cultivation.
\end{abstract}

